University of South Florida

DIGITAL COMMONS

Digital Commons @ University of

@ UNIVERSITY OF SOUTH FLORIDA

South Florida

Marine Science Faculty Publications

College of Marine Science

1999

\title{
Anomalous Warming in the Indian Ocean Coincident with El Niño
}

D. P. Chambers

University of Texas at Austin, donc@usf.edu

B. D. Tapley

University of Texas at Austin

R. H. Stewart

Texas A \& M University, College Station

Follow this and additional works at: https://digitalcommons.usf.edu/msc_facpub

Part of the Life Sciences Commons

\section{Scholar Commons Citation}

Chambers, D. P.; Tapley, B. D.; and Stewart, R. H., "Anomalous Warming in the Indian Ocean Coincident with El Niño" (1999). Marine Science Faculty Publications. 1427.

https://digitalcommons.usf.edu/msc_facpub/1427

This Article is brought to you for free and open access by the College of Marine Science at Digital Commons @ University of South Florida. It has been accepted for inclusion in Marine Science Faculty Publications by an authorized administrator of Digital Commons @ University of South Florida. For more information, please contact digitalcommons@usf.edu. 


\title{
Anomalous warming in the Indian Ocean coincident with El Niño
}

\author{
D. P. Chambers and B. D. Tapley \\ Center for Space Research, University of Texas at Austin
}

\author{
R. H. Stewart \\ Department of Oceanography, Texas A \& M University, College Station
}

\begin{abstract}
The TOPEX/POSEIDON altimeter has provided further evidence that interannual warming occurs in the Indian Ocean with a frequency similar to that of El Niño in the Pacific and has yielded important clues to the dynamics driving the warming. The signal is especially strong during the $1997 \mathrm{El}$ Niño. The altimeter observes long waves which move westward from the southeastern Indian Ocean at about the same time as westwardly wind anomalies appear in the east-central portion of the basin. The sea level peaks in the southwestern Indian Ocean and causes a sea level variation signal that is a near mirror image of El Niño in the eastern Pacific. Sea surface temperature data also show a similar correlation. An analysis of the altimeter data indicates significant variability in the Indian Ocean during the 1994 and 1997 E1 Niño events at the first and second baroclinic Rossby wave modes. Sea surface temperature and wind data suggest that the Indian Ocean warming has occurred during several previous E1 Niño events, particularly during the large events of 1982 and 1987. Based on these observations, it is suggested that the warming begins with wind-forced Rossby waves in the southeastern Indian Ocean associated with the Southern Oscillation, similar to the forcing of Kelvin waves which precede El Niño in the Pacific.
\end{abstract}

\section{Introduction}

Several recent studies have presented evidence which suggests that interannual variability of ocean heat storage occurs in the Indian Ocean with a frequency similar to El Niño in the Pacific [Tourre and White, 1995; Nicholson, 1997]. Nigam and Shen [1993] had previously noticed a small but significant warming in the western Indian Ocean during the 1983 and 1987 El Niño events but did not do an extensive study of the signal. Tourre and White [1995] were the first to specifically study the correlation between interannual warming in the Indian Ocean and El Niño in the Pacific, focusing on the events of 1983 and 1987. They found that surface warming in the Indian Ocean lagged the peak of El Niño by 6 months in 1983, but that the warming in 1987 occurred at approximately the same time as El Niño. Nicholson [1997] studied eight earlier E1 Niño cycles from 1948 to 1980 and found similar correlations between El Niño and anomalous surface warming in the Indian Ocean.

Tourre and White [1995] also studied variability in the total heat content of the upper $400 \mathrm{~m}$ and found a slightly different correlation. First, the maximum heat content occurred farther west than the maximum SST in the Indian Ocean. Second, the maximum heat content in the Indian Ocean occurred at about the same time as the maximum heat content in the eastern Pacific. From these observations, Tourre and White [1995] concluded that there is a slow eastward propagation of the warming signal from the western Indian Ocean to the east which begins at approximately the same time as El Niño, similar to the welldocumented eastward propagation in the Pacific [e.g., Philander, 1990].

Copyright 1999 by the American Geophysical Union.

Paper number 1998JC900085.

0148-0227/99/1998JC900085\$09.00
Although these studies indicate a correlation between the timing of warming events in the Indian Ocean and the Pacific, neither has documented the complete evolution of a warming event in the Indian Ocean, as has been done in the Pacific. Nor has either study fully documented the forces which would link the Pacific El Niño with the Indian Ocean warming. This is due partly to a lack of data. For instance, the expendable bathythermographs (XBT) network used in the previous studies are limited to only a few ship tracks that have a regular sampling interval (Figure 1).

To improve the sampling, we have examined sea level variability data from the TOPEX/POSEIDON altimeter satellite to examine the Pacific and Indian Oceans from 1993 to the beginning of 1998. Altimeter sampling is denser and more uniform than any in situ measurement. For TOPEX/POSEIDON (T/P), observations are made every $7 \mathrm{~km}$ along the ground track, and the largest separation between ground tracks is only $311 \mathrm{~km}$ at the equator (Figure 1). The ground track repeats every 10 days. The sea level data from the altimeter is well suited for studying changes in heat storage [White and Tai, 1995; Chambers et al., 1997; Wang and Koblinsky, 1997; Chambers et al., 1998a], since an increase in stored heat causes an increase in sea level. Other investigations have also shown that altimeter data can detect the El Niño warming in the Pacific [Miller et al., 1988; Boulanger and $F u, 1996]$, so it is reasonable to expect that the altimeter data will be able to detect any El Niño-related warming in the Indian Ocean if it occurs. During the span of the TOPEX/POSEIDON mission (September 1992 through January 1998 as of this writing), there have been two complete $\mathrm{El}$ Niño cycles [Goddard and Graham, 1997], and a third has matured during the summer and fall of 1997 [Climate Analysis Center, 1997a]. The event of 1997 is particularly interesting, because it appears to be as large or larger than the event in 1983 , the largest previously recorded. The more dense sampling of the altimeter data should provide a better insight into the evolution of any Indian Ocean warming event than can be deduced from the more limited XBT data. 


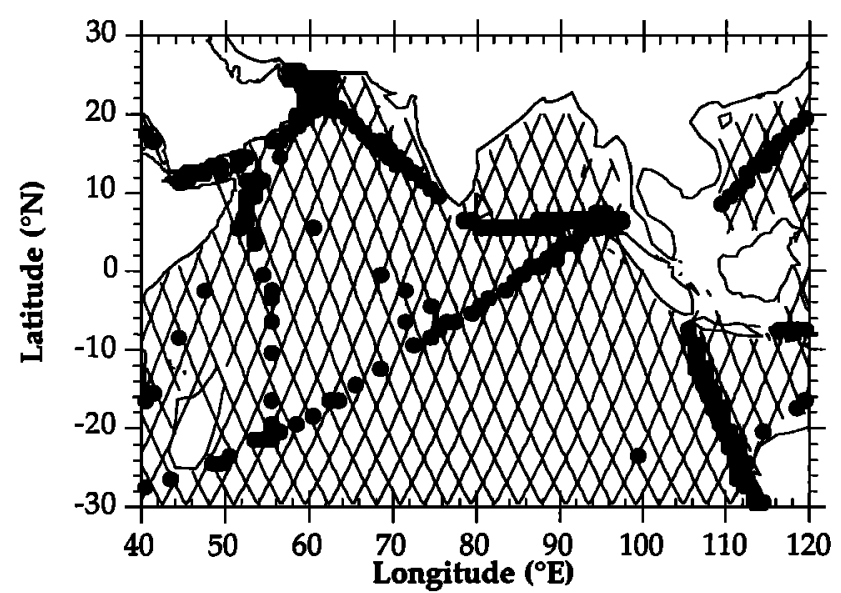

Figure 1. T/P ground track in Indian Ocean along with locations of XBT stations (circles) with more than 36 monthly observations in a 4-year period from 1992 to 1996.

To supplement the altimeter data and to verify the results, we have also examined the sea surface temperature (SST) data collected and processed by Reynolds [1988], and analyzed winds processed by Florida State University (FSU) [Legler and O'Brien, 1985; Stricherz et al., 1993]. This SST data set combines satellite and in situ data into weekly averages on a regular global grid from 1982 to the present, and the winds are monthly averages on a regular grid in the Indian Ocean and the tropical Pacific from 1971 to the present. Besides verifying the $\mathrm{T} / \mathrm{P}$ results, these data will also provide a useful tool for examining the correlation between the Pacific and Indian Oceans before the T/P mission was launched. We have limited SST data to only the Reynolds data set because it uses satellite measurements and so has a resolution similar to that of $T / P$. Earlier SST data from XBTs or ships will suffer from having large areas with no recordings and hence significant interpolation errors.

In the following section we will present a brief overview of data processing and filtering. The timing of interannual warming events and the location of peak warming will be examined in each basin using empirical orthogonal functions (EOFs), and the correlation between events in the Pacific and Indian Oceans will be discussed. Finally, a description of the development and evolution of the warming events which occurred during the 1994 and $1997 \mathrm{El}$ Niño events will be presented, including a discussion of how the sea level variations in the Pacific and Indian Oceans are dynamically linked via wind anomalies which force Kelvin waves in the Pacific and Rossby waves in the Indian Ocean.

\section{Data Processing}

For this study we have used TOPEX/POSEIDON altimeter data over the time period from December 21, 1992, through February 8, 1998. The altimeter data are from the second release Merged Geophysical Data Records and include all geophysical corrections, including the inverted barometer correction [Benada, 1997]. These data include improved orbits and geophysical corrections, including the ocean tide, pole tide, and sea state bias.

We have minimized errors due to along-track and cross-track geoid gradients by computing T/P sea level anomalies relative to a high-resolution mean sea surface estimated along the $T / P$ ground track [Chambers et al., 1998b]. The sea level anomaly (SLA) is the difference between the total sea surface height measurement and the mean sea surface measurement at a particular point. Since we are interested in interannual variations, the sea level anomalies are detrended at each point along the ground track by removing a linear trend and annual and semiannual sinusoids estimated using a least squares fit. It is necessary to remove both annual and semiannual terms in the Indian Ocean in particular because of variations associated with the twice-per-year monsoons. The data are then averaged over each repeat cycle into a uniform $1^{\circ}$ grid over the Indian Ocean $\left(30^{\circ} \mathrm{S}\right.$ to $30^{\circ} \mathrm{N}, 40^{\circ} \mathrm{E}$ to $\left.120^{\circ} \mathrm{E}\right)$ and the Pacific Ocean $\left(30^{\circ} \mathrm{S}\right.$ to $30^{\circ} \mathrm{N}, 130^{\circ} \mathrm{E}$ to $290^{\circ} \mathrm{E}$ ). Since the cross-track spacing of the T/P ground track is nearly $3^{\circ}$, these grids will have missing data. Missing data values are interpolated and the averaged values are smoothed using a Gaussian weighted filter described by Chambers et al. [1997]. The filter attenuates spatial signals of less than $1200 \mathrm{~km}$ zonally and $400 \mathrm{~km}$ meridionally. After this processing, there are 186 grids for each basin, since three repeat cycles contain no data, due to a computer malfunction in cycle 118 , missing water vapor and ionosphere measurements in cycle 174, and unreleased POSEIDON data for cycle 197. The accuracy of the sea level anomalies is approximately $3 \mathrm{~cm}$ based on comparisons with tide gauges [Chambers et al., 1998c].

The SST data are a combined set of satellite and in situ measurements, optimally interpolated to a $1^{\circ}$ grid [Reynolds and Smith, 1994]. No further spatial filtering has been done to the data, but weekly averages have been averaged into monthly means, and a long-term mean (1982 to 1996) has been removed to create SST anomalies. These data were also detrended by removing a linear trend and annual and semiannual sinusoids for each grid point.

The FSU wind data come from all available wind measurements from ships, buoys, and other oceanic sites and are averaged into monthly $1^{\circ}$ grids for the Indian Ocean and $2^{\circ}$ grids for the Pacific [Legler and O'Brien, 1985; Stricherz et al., 1993]. The data are expressed as zonal and meridional pseudostress vectors (wind components multiplied by the wind magnitude). A pseudostress vector of $60 \mathrm{~m}^{2} \mathrm{~s}^{-2}$ corresponds to $1 \mathrm{dyn} \mathrm{cm}^{-2}$ assuming a drag coefficient of $1.4 \times 10^{3}$ and an air density of 1.2 $\mathrm{kg} \mathrm{m}^{.3}$. As with the SST and sea level data, the gridded wind data have been detrended by removing a linear trend and annual and semiannual sinusoids estimated at each grid point.

\section{Analysis and Discussion}

\subsection{Correlation Between Indian Ocean Warming and EI Niño}

To better observe the correlation between interannual signals associated with El Niño, empirical orthogonal functions (EOFs) have been computed, similar to the analysis by Tourre and White [1995]. EOFs separate the gridded data into distinct orthogonal modes which concentrate as much of the variance as possible into a set of orthogonal spatial maps and time series [Preisendorfer, 1988]. In this analysis the EOFs are extracted using the covariance measure, and the spatial maps have been normalized, and the time series has been scaled so that

$$
\eta(x, t)=\sum_{k=1}^{N} \alpha_{k}(t) \beta_{k}(x)
$$

where $\eta$ is the SLA or SST measurement, $x$ is the twodimensional space domain, $t$ is time, $k$ is the EOF mode (equal to the number of spatial grids), $\alpha_{k}(t)$ is the time series for each EOF mode, and $\beta_{k}(x)$ is the spatial map for each EOF mode. The strength of the EOF method is that it allows one to observe where and when the largest sea level or SST variations occur in each mode, and the modes are arranged from largest percentage of the variability explained to the smallest. Since the annual and semiannual variability has been removed, Mode 1 in the Pacific is dominated by the El Niño signal (Figure 2).

In the Pacific Ocean, Mode 1 accounts for over $50 \%$ of the interannual variance in the sea level data and $40 \%$ of the variance in the SST data. The spatial map for both the SSTs and sea levels 

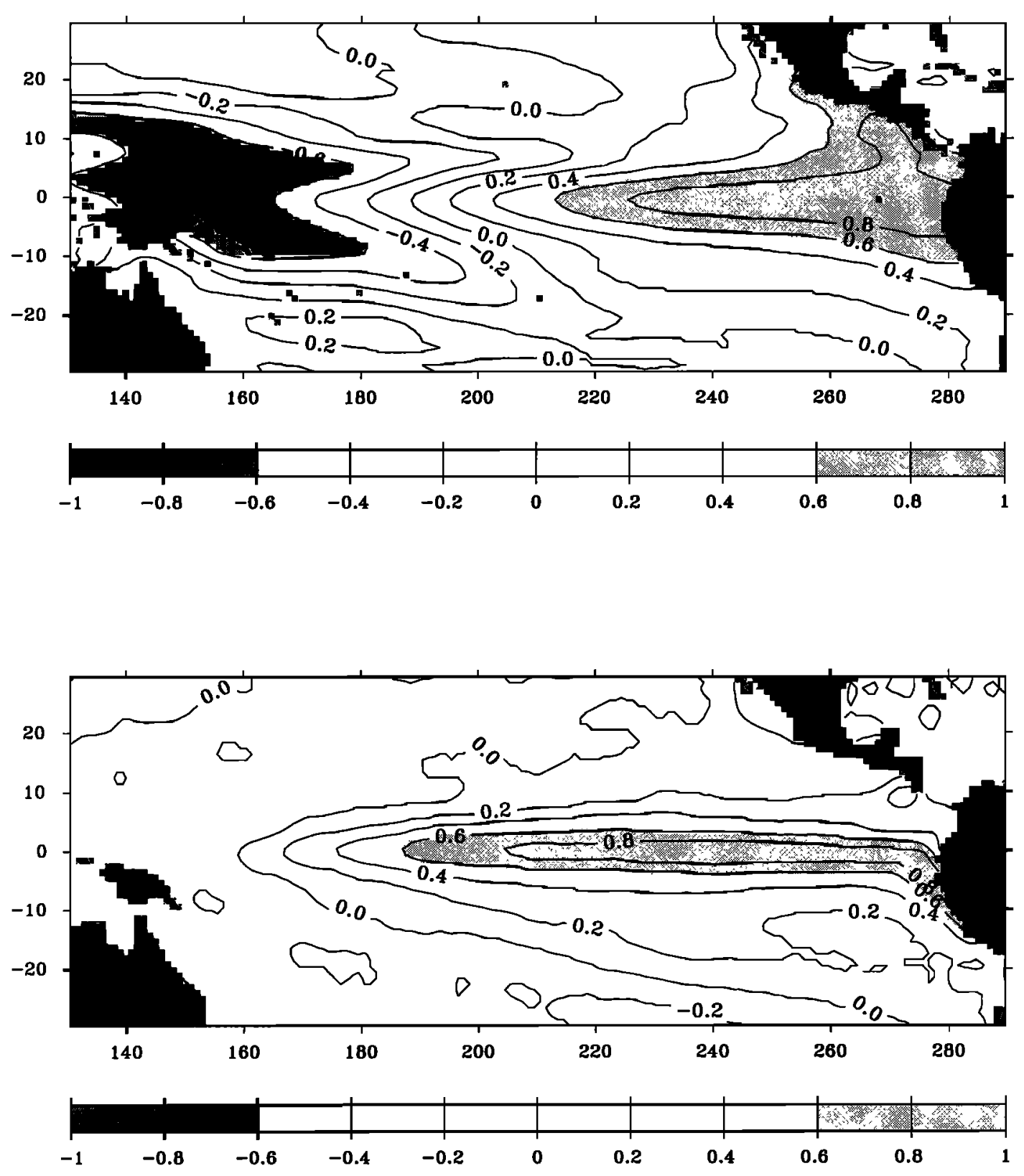

Figure 2. Pacific Ocean EOF Mode 1 spatial maps for (top) T/P sea-level anomalies, 1993-1998, and (bottom) sea surface temperature, 1982-1997. The maps have been normalized and extreme values have been shaded.

have the highest positive values along the equatorial Pacific, in a tongue extending from the west coast of Peru to the date line. This is the classic signature of El Niño in the Pacific. Both maps also show that the variation in the western Pacific is out of phase with the eastern Pacific, although the magnitude is much larger in the T/P data. Combining the spatial map with the time series of Mode 1 (Figure 3), one sees that the central and eastern Pacific sea levels were higher than normal in spring 1993, summer/fall 1994, and summer/fall 1997. The SSTs show similar positive anomalies. The timing correlates well with El Niño events in these years [Goddard and Graham, 1997; Climate Analysis Center, 1997a]. The extended SST time series also shows the effects of the 1983, 1987, and 1992 El Niños in the Pacific (Figure 4). Both of the spatial maps agree with similar maps from the analysis of Tourre and White [1995].

Figure 5 shows similar EOF maps for the Indian Ocean. Mode 1 accounts for over $41 \%$ of the interannual variance in the sea level data and about $20 \%$ in the SST data. The sea level map shows the largest values occur south of the equator, between $5^{\circ} \mathrm{S}$ and $10^{\circ} \mathrm{S}$ in the western portion of the basin. The SST map shows a peak south of the equator as well, although displaced southwestward, as well as a second peak north of the equator. The sea level data also have a small peak north of the equator but not in the same location as the SST data. Similar to the Pacific, the sea level map has large out-of-phase signals opposite of the positive anomaly, whereas the SST map does not. Since the sea level data are sensitive to temperature changes throughout the water column, a significant part of the difference is due to larger cooling at depth than at the surface, although some of the signal can be explained by interannual salinity changes [Delcroix and Picaut, 1998; Chambers et al., 1998a].

The time series of the Indian Ocean EOF modes (Figures 3 and 4) show significant positive SST and sea level anomalies at approximately the same time in 1994 and 1997 as the El Niño warming in the Pacific. Although the Indian Ocean SST anomaly in 1993 is not much different from zero, there is a $0.5^{\circ} \mathrm{C}$ change 

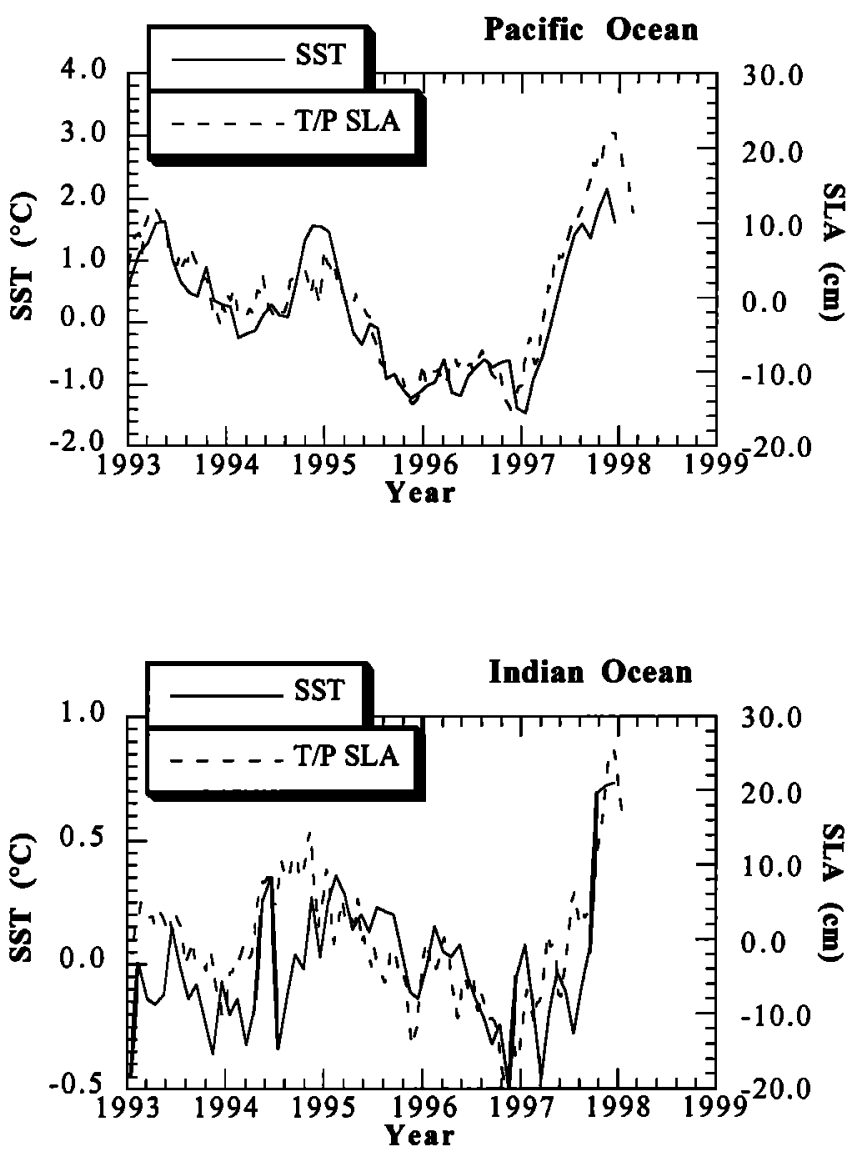

Figure 3. EOF Mode 1 time series for (top) Pacific Ocean and (bottom) Indian Ocean. Data have been scaled to SLA (dashed line) and SST anomalies (solid line).

in SST from the beginning to the middle of 1993, approximately at the same time as El Niño warming in the Pacific. In 1994, there are two peaks in SST in the Indian Ocean. The first is in April and May, followed by a sharp decline in SST, followed by another rise in October with extended positive SST anomalies throughout the first half of 1995 . During the time of these two peaks, sea level anomalies in the region remained high.

Although the EOF Mode 1 maps in the Pacific agree with those of Tourre and White [1995], the maps in the Indian Ocean (Figure 5) do not. Tourre and White [1995] show that the heat storage (analogous to sea level) and the SSTs both have a maximum near the equator. It does not appear that the more recent data used for this analysis is the source of the difference. When the EOFs were recomputed for the Indian Ocean with SST data only from 1982 to 1991 (similar to the time span of Tourre and White [1995]), the Mode 1 map is very similar to that using data from 1982 to 1997 (Figure 6). This leads us to believe that the difference is in the sampling of the XBT data used by Tourre and White [1995]. Although the Pacific Ocean had adequate XBT coverage in the eastern Pacific along the equator, the coverage in the southern Indian Ocean is relatively poor (Figure 1), especially in the region where the T/P and SST measurements show the largest change. Since the largest heating anomaly occurs in the area where there was little or no XBT data, it is likely that the peak of the EOFs computed from the XBT measurements was biased to the other high anomalies along the equator.

The timing of the surface warming in the southwestern Indian Ocean (from the SST data) occurred very close in time to the warming in the eastern Pacific during several of the El Niño events from 1982 to 1998 , particularly during the large events of
1983, 1987, and 1997 (Figure 4). The warming in the Indian Ocean lagged the warming in the Pacific by about 3 to 5 months, based on the time the SST anomalies pass through zero. The timing of the peak warming is harder to asses in the Indian Ocean because of the more variable time series, but based on the timing of the largest positive SST anomalies, the heating in the Indian Ocean peaked between 7 and 9 months after that in the Pacific during 1983 and 1987, but at about the same time in 1997.

There is also some correlation during the smaller El Niño events of the 1990s. SSTs peaked in the Pacific at the beginning of 1992, but peaked nearly a year earlier in the western Indian Ocean. The lack of a positive SST anomaly in the Indian Ocean during 1993 has already been noted. During 1994, extended positive SST anomalies began appearing in the Indian Ocean at about the same time as SST anomalies in the eastern Pacific, but peaked later. Also, the duration of positive SST anomalies was substantially longer in the Indian Ocean than in the Pacific during the 1987 and 1994 El Niño events.

The timing of the heat storage (i.e., sea level) variations is slightly different, based on the limited amount of data available from T/P. The peak Indian Ocean sea level occurred before the peak in the Pacific during 1994 and the start of extended positive anomalies began earlier, based on the criteria used previously. During 1993 and 1997, however, sea level in the Pacific began increasing before sea level in the Indian Ocean, although sea level peaked at nearly the same time (Figure 4 ). It is also
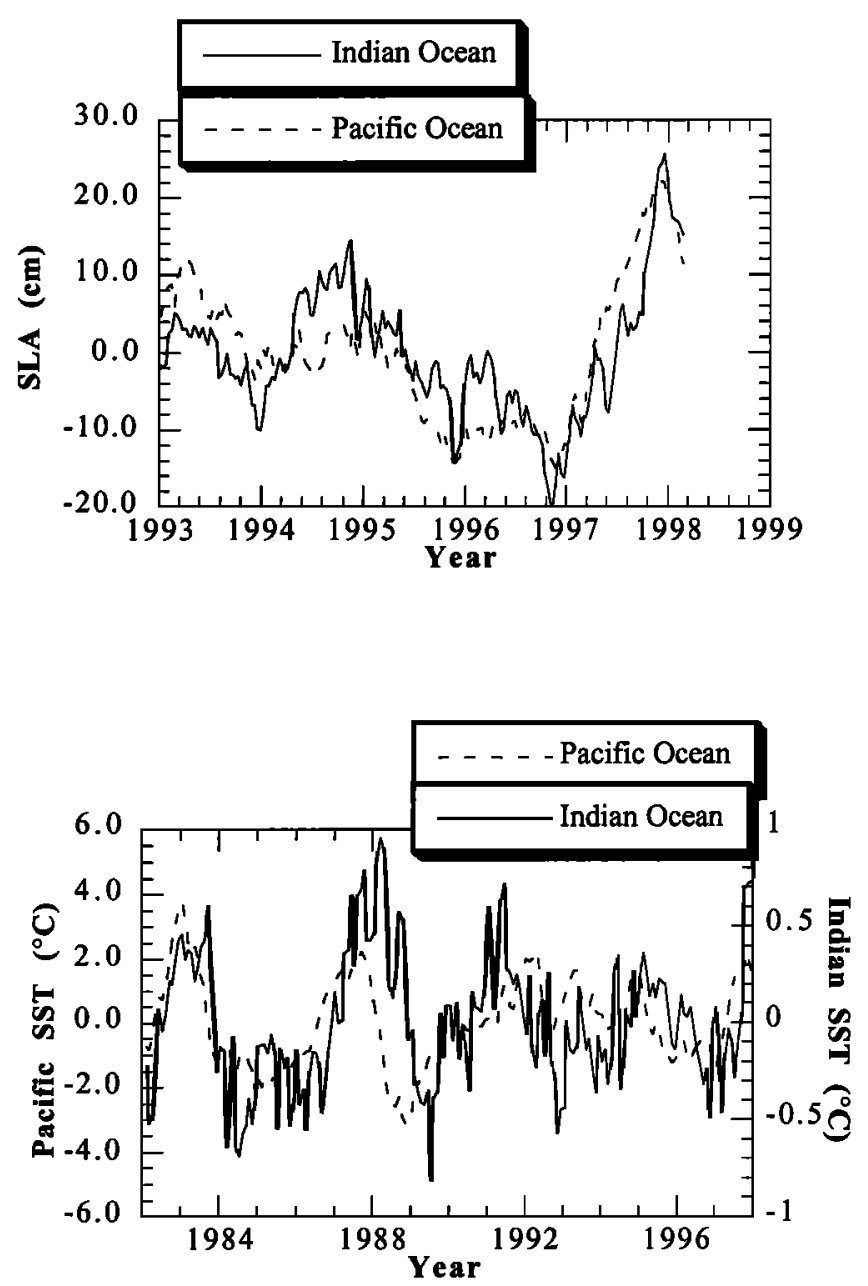

Figure 4. EOF Mode 1 (top) SLA time series and (bottom) SST time series for both basins: Indian Ocean (solid line) and Pacific Ocean (dashed line). Note that the scales for the Indian Ocean and Pacific SSTs are different. 

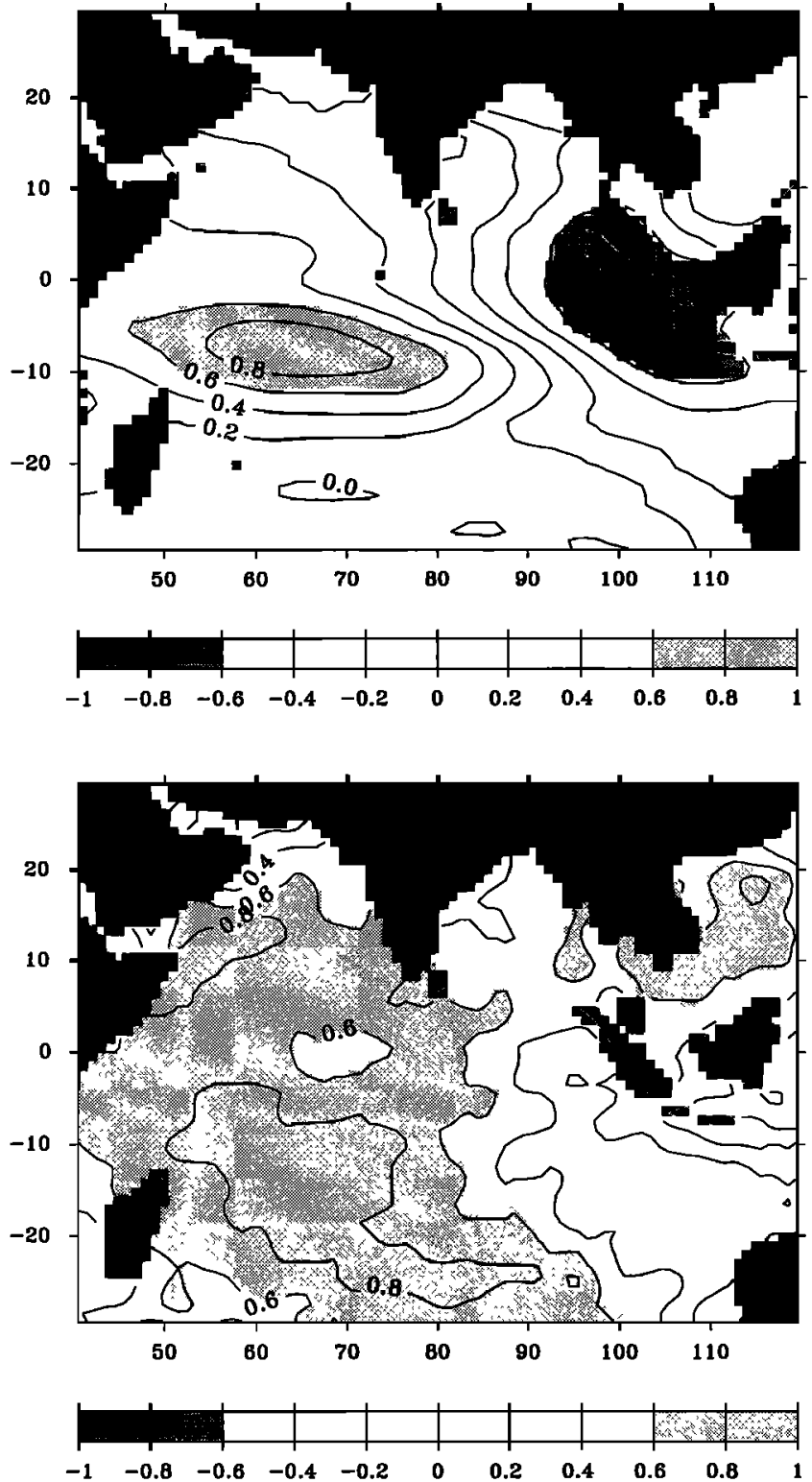

Figure 5. Indian Ocean EOF Mode 1 spatial maps for (top) T/P sea-level anomalies, 1993-1998 and (bottom) sea surface temperature, 1982-1997. The maps have been normalized and extreme values have been shaded.

interesting to note the relative sizes of sea level and SST anomalies in the two basins. The SST changes in the Pacific are much larger than the variations in the Indian Ocean, by as much as 2 to 3 times larger (Figure 4). Part of this difference could be related to the mean temperatures in the two regions, though. The mean temperature in the western Indian Ocean is about $27.5^{\circ} \mathrm{C}$, more than $2^{\circ} \mathrm{C}$ higher than the mean temperature in the eastern Pacific, which means that the total SST during the warming is about the same in both basins. On the other hand, sea level variations (indicative of total heating changes in the upper layer) are similar in magnitude between the two oceans (Figure 4), although the variations in the Indian Ocean had amplitudes significantly larger in 1994/1995. This suggests that although the surface temperature changes in the Indian Ocean might not have been as large as those in the Pacific, internal warming was just as great.

Also, sea level began increasing before SST in both basins, based on the beginning of positive anomalies during the 1993,
1994, and 1997 El Niños (Figure 3). The difference is between 3 to 5 months in the Pacific and 7 to 9 months in the Indian Ocean. This suggests the warming begins deeper in the mixed layer, then propagates to the surface. This has been observed in the Pacific during El Niño, as internal Kelvin waves introduce subsurface currents which advect warm water eastward [Philander and Pacanowski, 1980; Harrison and Schopf, 1984] along the thermocline. The fact that a similar lag occurs in the Indian Ocean suggests that a comparable mechanism may be responsible for the warming there.

\subsection{Forcing of Indian Ocean Warming}

Tourre and White [1995] speculate that a possible driving mechanism for the Indian Ocean warming might be wind anomalies and Rossby waves, similar to the eastwardly wind anomalies in the central Pacific which force Kelvin waves and can lead to El Niño several months later [Graham and White, 1988]. The driving force behind these wind anomalies in the Pacific has been well established as the Southern Oscillation, an interannual shift in the atmospheric pressure over the western Pacific [Graham and White, 1988].

Normally, atmospheric pressure over the western Pacific is lower than the pressure in the east. This pressure differential causes the winds to blow from the east to the west across the equatorial Pacific: the trade winds. Every 3 to 7 years, however, the atmospheric pressure increases over the western Pacific and decreases over the eastern Pacific. This causes normal winds to become either weaker from east to west, or to sometimes reverse and blow from west to east. These wind variations lead to El Niño warming in the eastern Pacific.

Since the anomalous high-pressure system extends into the eastern portion of the Indian Ocean, it is not surprising that it can cause wind anomalies in the Indian Ocean as well. The wind anomalies in the Pacific are strongest along the equator at about the date line and are generally eastwardly just before peak El Niño warming, while in the Indian Ocean the wind anomalies are strongest along the equator near $80^{\circ} \mathrm{E}$, but are westwardly in the summer months before the peak of El Niño [Nigam and Shen, 1993]. That is, the winds tend to blow in the opposite direction in the Indian Ocean from the Pacific along the equator (Figure 7). Although the wind anomalies are not always strongest around

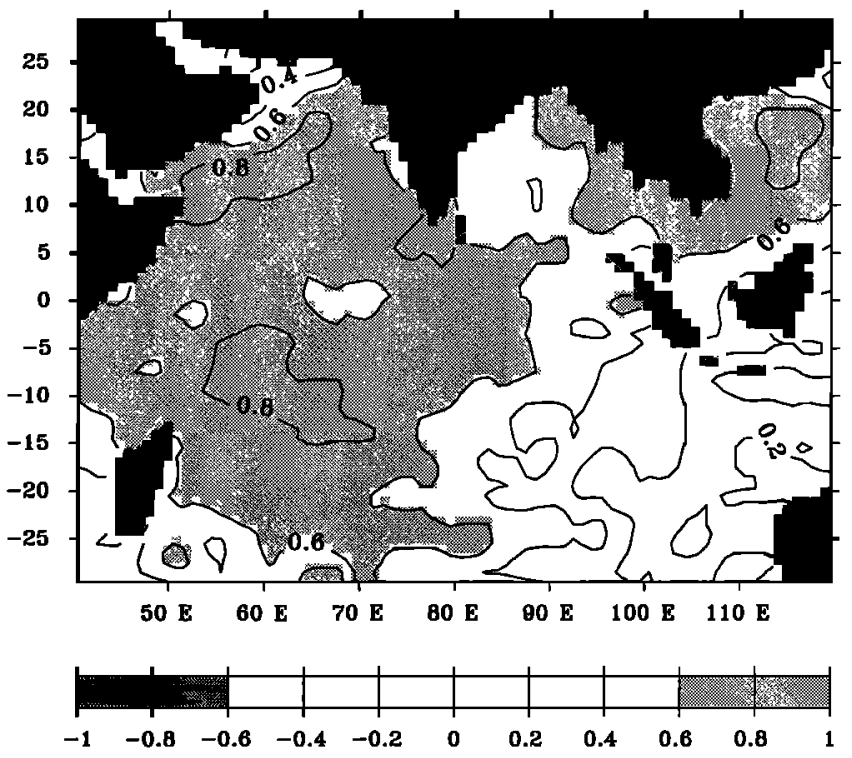

Figure 6. Indian Ocean EOF Mode 1 spatial maps for sea surface temperature, 1982-1991. The maps have been normalized and extreme values have been shaded. 
$0^{\circ} \mathrm{N}, 80^{\circ} \mathrm{E}$ in the Indian Ocean during El Niño development, there are generally significant westwardly anomalies in the region [Nigam and Shen, 1993]. Note that although the wind data shown in Figure 7 contain components unrelated to El Niño, the largest anomalies have occurred during major El Niño events of the last 25 years, as indicated by the strong correlation with the Southern Oscillation Index (SOI; Figure 7). The wind anomalies do not occur at exactly the same relative time in the Indian and Pacific Oceans; sometimes the wind anomalies begin first in the Pacific, sometimes in the Indian Ocean. However, the overall correlation between the wind anomalies in each basin is high, about 0.6.

The wind anomalies are well correlated with the sea level variations in both oceans determined from the EOF analysis (Figure 8). One can also see correlations between the wind strength and the size of the sea level anomaly. In 1993, the westwardly wind anomalies in the Indian Ocean were relatively weak and there had been stronger than normal eastwardly winds several months earlier. This corresponded with little warming in the Indian Ocean during 1993. In contrast, during the 1994 event the westwardly wind anomalies in the Indian Ocean were nearly twice as large as the eastwardly wind anomalies in the Pacific.
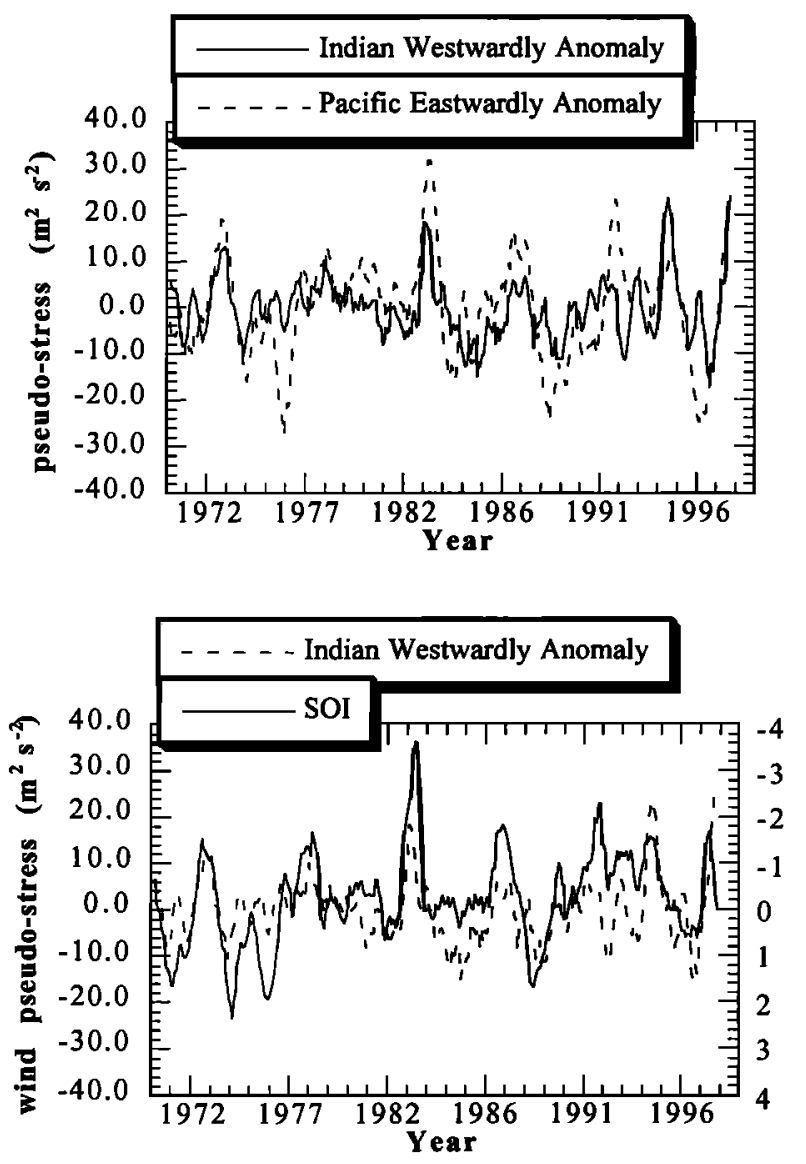

Figure 7. Average zonal wind pseudo-stress anomalies for the Indian Ocean (solid line) and Pacific (dashed line) from the (top) FSU monthly wind database and (bottom) Southem Oscillation Index (SOI). The range of the SOI has been inverted to emphasize correlations during El Niño events, since the SOI has large negative values during El Niño. Winds in the Indian Ocean are averaged from $5^{\circ} \mathrm{S}$ to $5^{\circ} \mathrm{N}$ and $80^{\circ} \mathrm{E}$ to $100^{\circ} \mathrm{E}$. Winds in the Pacific Ocean are averaged from $5^{\circ} \mathrm{S}$ to $5^{\circ} \mathrm{N}$ and $180^{\circ} \mathrm{W}$ to $160^{\circ} \mathrm{W}$. Positive values indicate eastwardly wind anomalies in the Pacific and westwardly wind anomalies in the Indian Ocean. All time series have been smoothed using a 5-month runningmean boxcar filter.
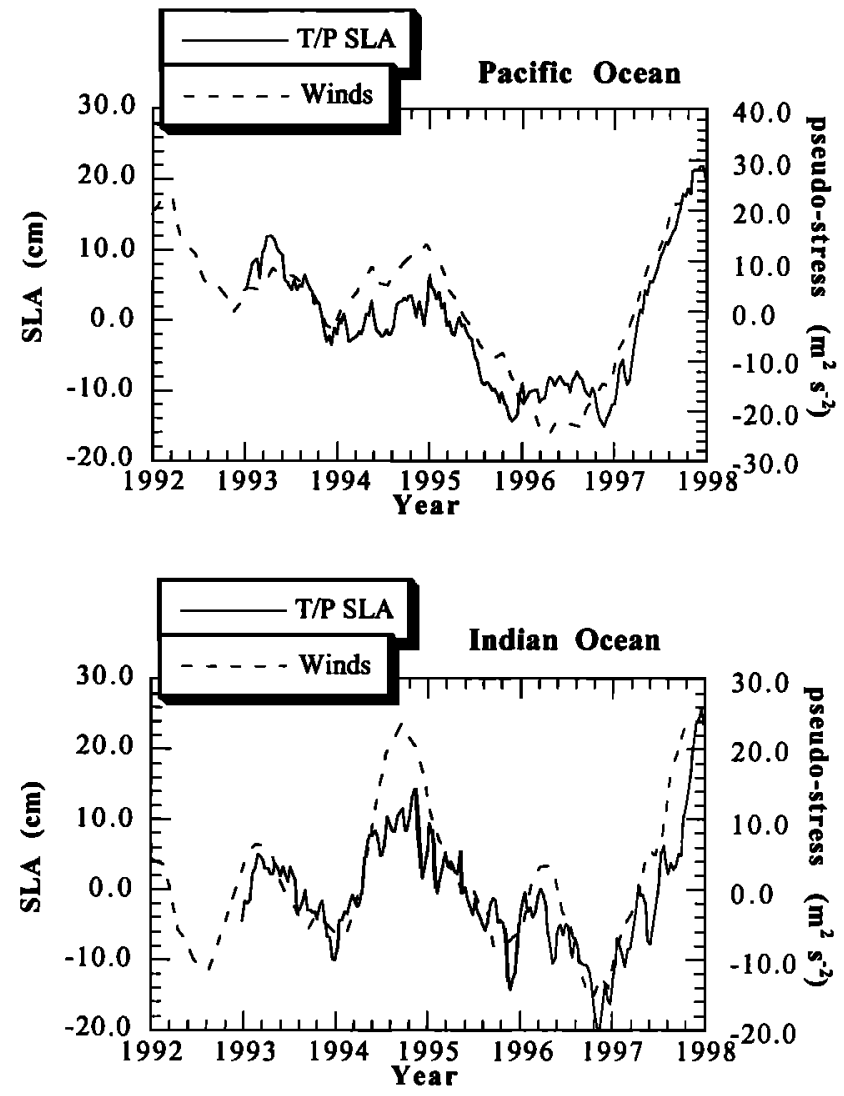

Figure 8. Winds from Figure 7 plotted against the SLA EOF Mode 1 time series in the (top) Pacific and (bottom) Indian Oceans.

This corresponded with larger sea level variations in the Indian Ocean than in the Pacific. During 1997, the wind anomalies had similar magnitudes in each ocean, as did the sea level variations.

It is known that anomalous winds such as these can force internal Kelvin and Rossby waves in the ocean [Gill, 1982], and that in the Pacific Ocean the Kelvin waves appear to deepen the thermocline in the eastern Pacific preceding the peak of El Niño and help advect warm water eastward along the equator below the surface. Since there are similar interannual wind anomalies in the Indian Ocean, it is likely that there is a similar oceanic adjustment which can explain the warming in the Indian Ocean and the correlation with El Niño. We turn to the T/P data to examine in more detail the ocean's response to the anomalous wind forcing in 1994 and 1997.

\subsection{Evolution of 1994 and 1997 El Niño Events}

The real strength in the T/P data compared to the XBT data used in the previous analyses is that it can be used to produce detailed maps of sea level variations at a consistent 10-day sample. This enables one to study changes in the ocean caused by Kelvin waves, Rossby waves, and El Niño with remarkable precision. These types of waves have been observed previously in altimetry data [Miller et al., 1988; Boulanger and Fu, 1996].

In 1994, a strong downwelling Kelvin wave began moving eastward along the equator in the Pacific following an eastwardly wind burst in July [Boulanger and $F u, 1996]$. Several more Kelvin waves were also forced by later wind changes, and by October, most of the eastern Pacific had warmed and the El Niño was peaking (Figure 9). In the Indian Ocean, however, the wind bursts were even stronger than in the Pacific, and sustained westwardly wind anomalies began several months before the 
Augugt 81994

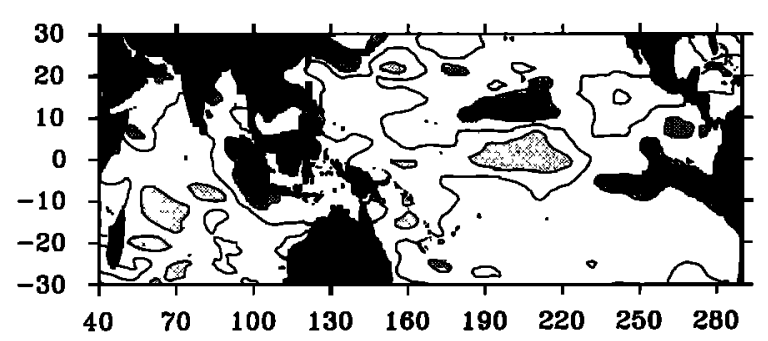

December 51994

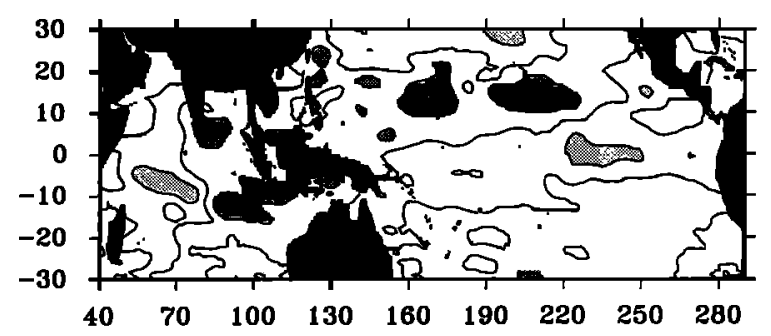

September 71994

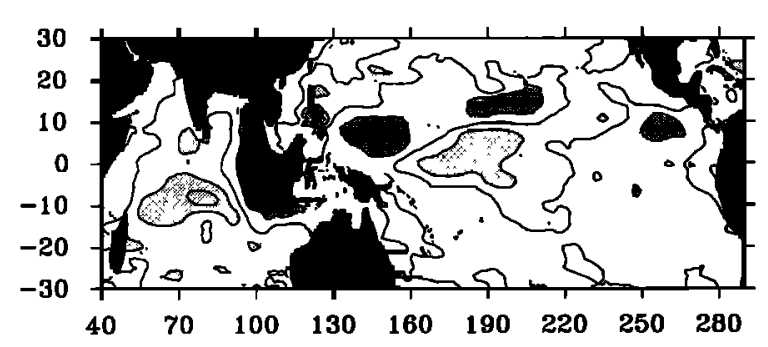

January 41995

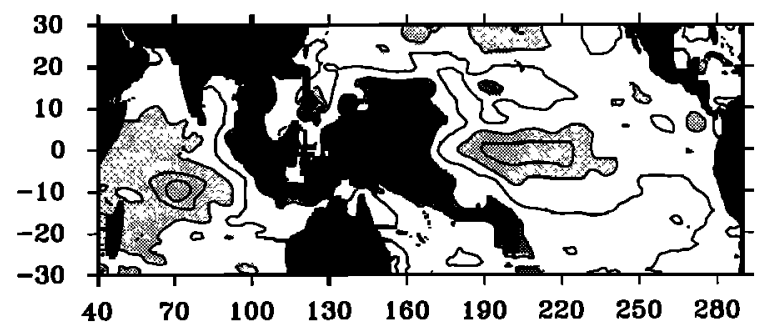

October 61994

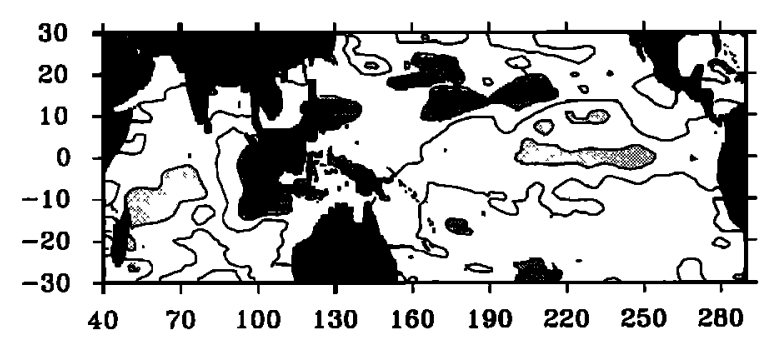

February 21995

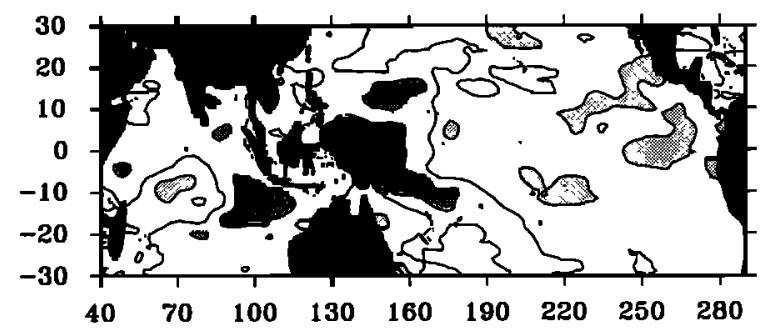

November 51994

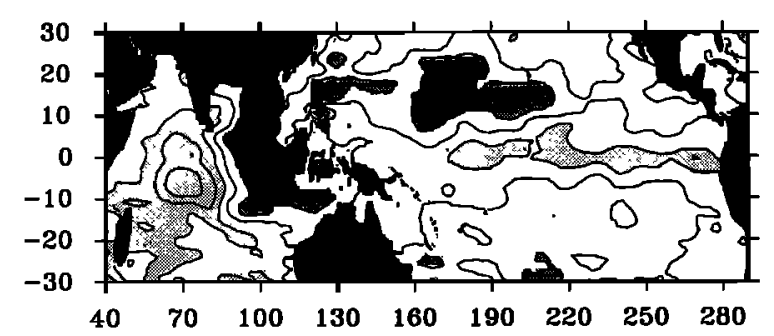

March 41995

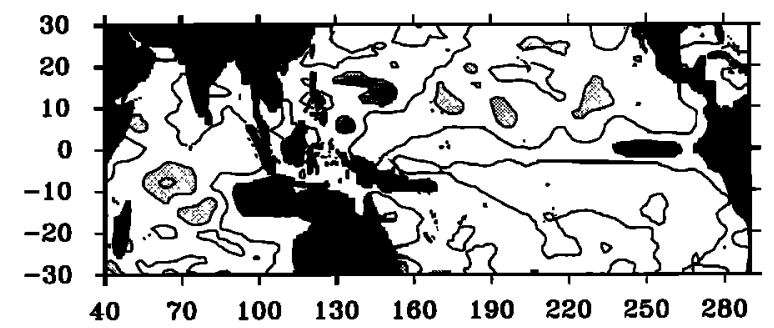

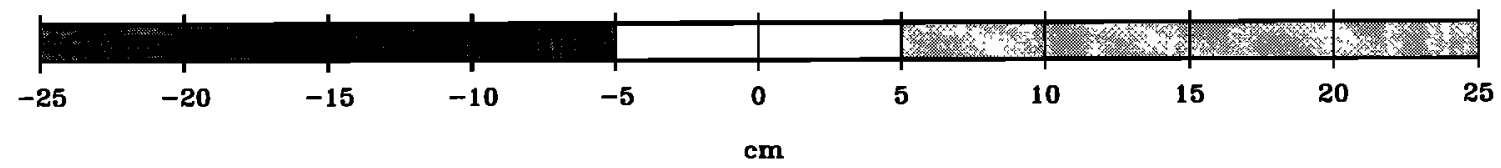

Figure 9. Sea level anomalies in Indian and Pacific Oceans from T/P during 1994/1995 with linear trend and annual and semiannual signals removed. Contour interval is $5 \mathrm{~cm}$. Anomalies smaller than $-5 \mathrm{~cm}$ have been shaded dark gray and anomalies greater than $5 \mathrm{~cm}$ have been shaded light gray.

wind anomalies in the Pacific. In April, at about the time of the first strong westwardly wind burst in the Indian Ocean, large positive sea level anomalies began developing around $15^{\circ} \mathrm{S}$, $80^{\circ} \mathrm{E}$. The anomalies moved slowly westward, and in July and August another region of positive sea level anomalies began forming farther north and east at about $90^{\circ} \mathrm{E}$ (Figure 9). The second group of anomalies also began to move slowly westward and south. At the same time, the sea level dropped significantly along the west coast of Indonesia, which suggests increased upwelling of colder water from the deeper ocean. Wind 
July 41997

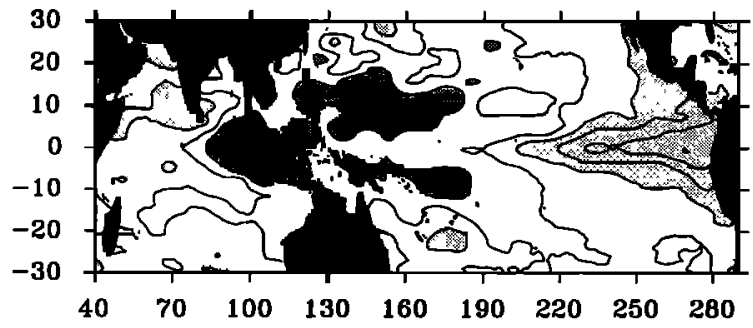

August 31997

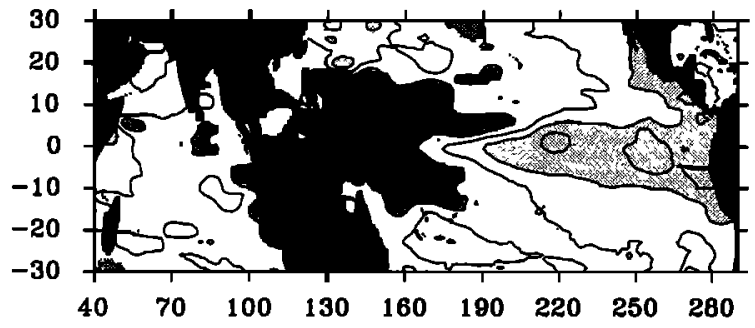

September 11997

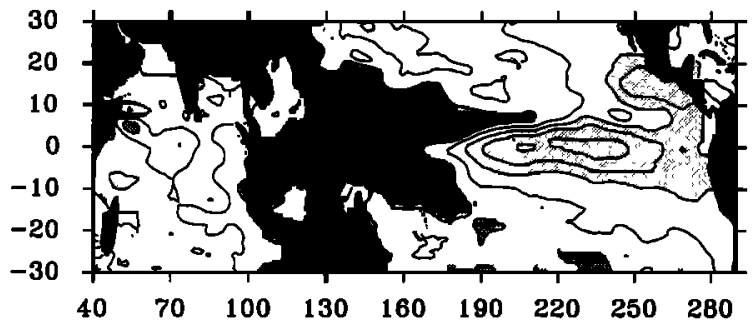

October 11997
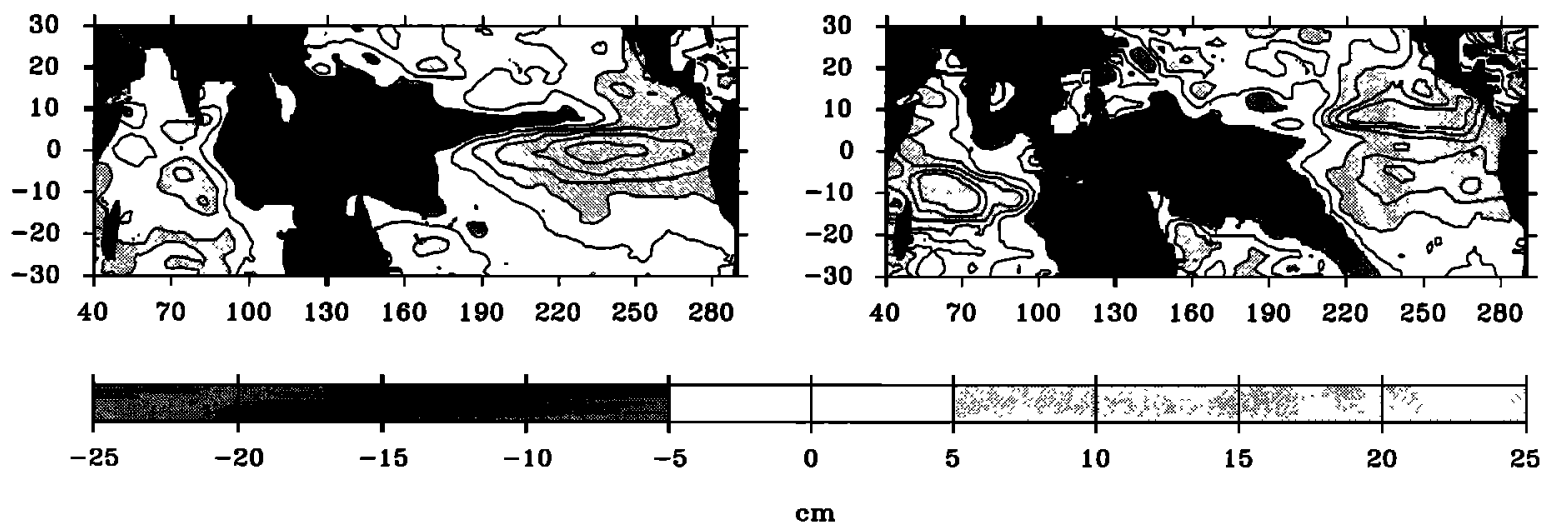

October 311997

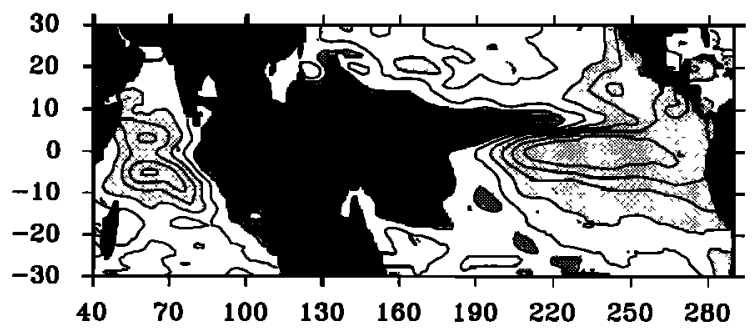

November 301997

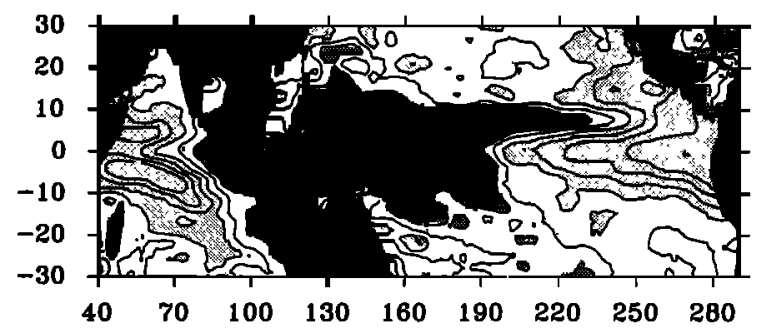

December 291997

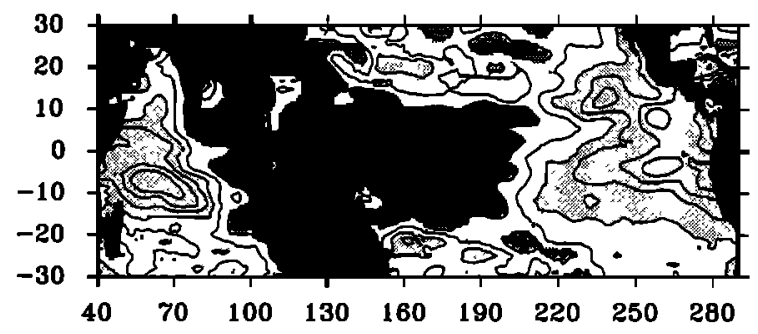

January 281998

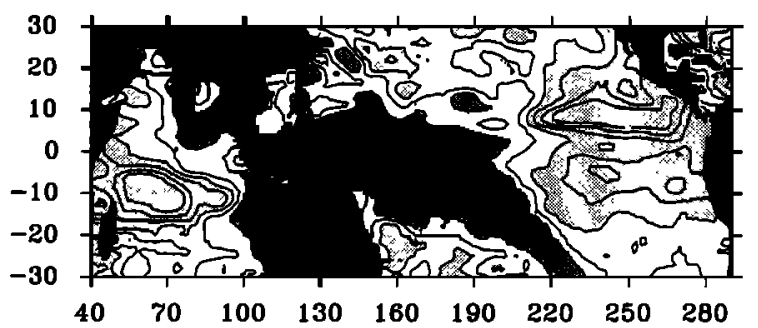

25

Figure 10. Sea level anomalies in Indian and Pacific Oceans from T/P during 1997/1998 with linear trend and annual and semiannual signals removed. Contour interval is $5 \mathrm{~cm}$. Anomalies smaller than $-5 \mathrm{~cm}$ have been shaded dark gray and anomalies greater than $5 \mathrm{~cm}$ have been shaded light gray.

observations support this conclusion [Climate Analysis Center, 1994, Fig. T26], as the winds west of Indonesia were blowing anomalously to the northwest parallel to the coast, which would cause Ekman transport of the warmer surface waters towards the high anomaly in the south-central Pacific, and upwelling from below to replace the water. This transport of warm water away from the coast of Indonesia most likely helped maintain the higher sea levels in the south-central Indian Ocean.

From November through January 1995, the sea levels in the west-central Indian Ocean were as much as $15 \mathrm{~cm}$ higher than the 
annual mean, with the largest values occurring south of the equator at about $7^{\circ}-9^{\circ} \mathrm{S}$ (Figure 9). From November to March 1995 , the large pool of warm water continued to move south and westward. At the same time in the Pacific, the El Niño event was dissipating; from November to March the sea level in the eastern Pacific dropped by about $10 \mathrm{~cm}$. By March the sea level had dropped below the mean, and the only residual signs of the El Niño event were reflected Rossby waves north and south of the equator [Boulanger and $F u, 1996$ ]. The Rossby waves continued to move westward across the Pacific throughout the spring and early summer of 1995 . Although the warming event in the Pacific dissipated fairly rapidly after it developed, the event in the Indian Ocean lingered. As late as June 1995, sea levels over a large region of the southwestern Indian Ocean were more than $6 \mathrm{~cm}$ higher than normal for this time of year.

The $1997 \mathrm{El}$ Niño caused much larger sea level variations in both the Pacific and Indian Oceans than did the 1994 event (Figure 10). Eastwardly wind bursts early in the year caused several Kelvin waves to form in the Pacific; by May, sea level was more than $10 \mathrm{~cm}$ higher than normal over a large region of the eastern Pacific. By July, sea level was nearly $20 \mathrm{~cm}$ higher than normal in the eastern Pacific, and the positive anomalies extended westward past $200^{\circ} \mathrm{E}$. The sea level began to drop in the far eastern Pacific in August (Figure 10), and by September the region of maximum sea level had moved westward by nearly $50^{\circ}$ in longitude.

During all this time, there was little indication of anomalous warming in the Indian Ocean. However, the winds changed dramatically again in October. For the first time during the 1997 El Niño, large wind anomalies occurred in both the central Indian Ocean and the central Pacific for a sustained period [Climate Analysis Center, 1997b, Fig. T19]. The winds caused another Kelvin wave in the eastern Pacific; sea level anomalies moved eastward and grew larger between October and November. By early December, sea level in the far eastern Pacific was more than $30 \mathrm{~cm}$ above normal (Figure 10).

At the same time in the Indian Ocean, large sea level anomalies appeared between $5^{\circ} \mathrm{S}$ and $10^{\circ} \mathrm{S}$ at $80^{\circ} \mathrm{E}$ and began moving westward. There was corresponding westward movement north of the equator, albeit with a smaller amplitude. By November the sea level in the southwestern region of the Indian Ocean between $10^{\circ} \mathrm{S}$ to $0^{\circ} \mathrm{N}$ and $40^{\circ} \mathrm{E}$ to $70^{\circ} \mathrm{E}$ was as much as $25 \mathrm{~cm}$ higher than normal. The peak interannual variability in the Indian Ocean occurred around $7^{\circ} \mathrm{S}$ in both 1994 and 1997. By examining the data in this region as a function of time, the westward movement of positive sea level anomalies in both 1994 and in 1997 is readily apparent (Figure 11). Figure 11 indicates two waves in 1994 and one in 1997.

\subsection{Analysis of Rossby Waves}

Such westward movement is indicative of Rossby waves, which have been observed throughout the oceans [Chelton and Schlax, 1996] and particularly in the Indian Ocean associated with annual wind variations [Yang et al., 1998]. Thus observations of Rossby waves associated with anomalous wind stresses are expected. However, we wish to verify whether the $\mathrm{T} / \mathrm{P}$ measurements are consistent with what is known about Rossby wave variability. Theoretically, the surface elevations caused by linear baroclinic planetary waves can be separated into modes that have a distinct meridional structure [Delcroix et al., 1991]. Mode 0 is an equatorial Kelvin wave and has eastward phase speed, while the remaining modes are Rossby waves with westward phase speed. For instance, the meridional structure of the first baroclinic mode Rossby wave has symmetric peaks at $5^{\circ} \mathrm{N}$ and $5^{\circ} \mathrm{S}$, while the second mode has asymmetric peaks at latitudes slightly poleward (Figure 12).

If the sea level variability observed by $T / P$ is due to Rossby waves, then one would expect that the meridional structure would
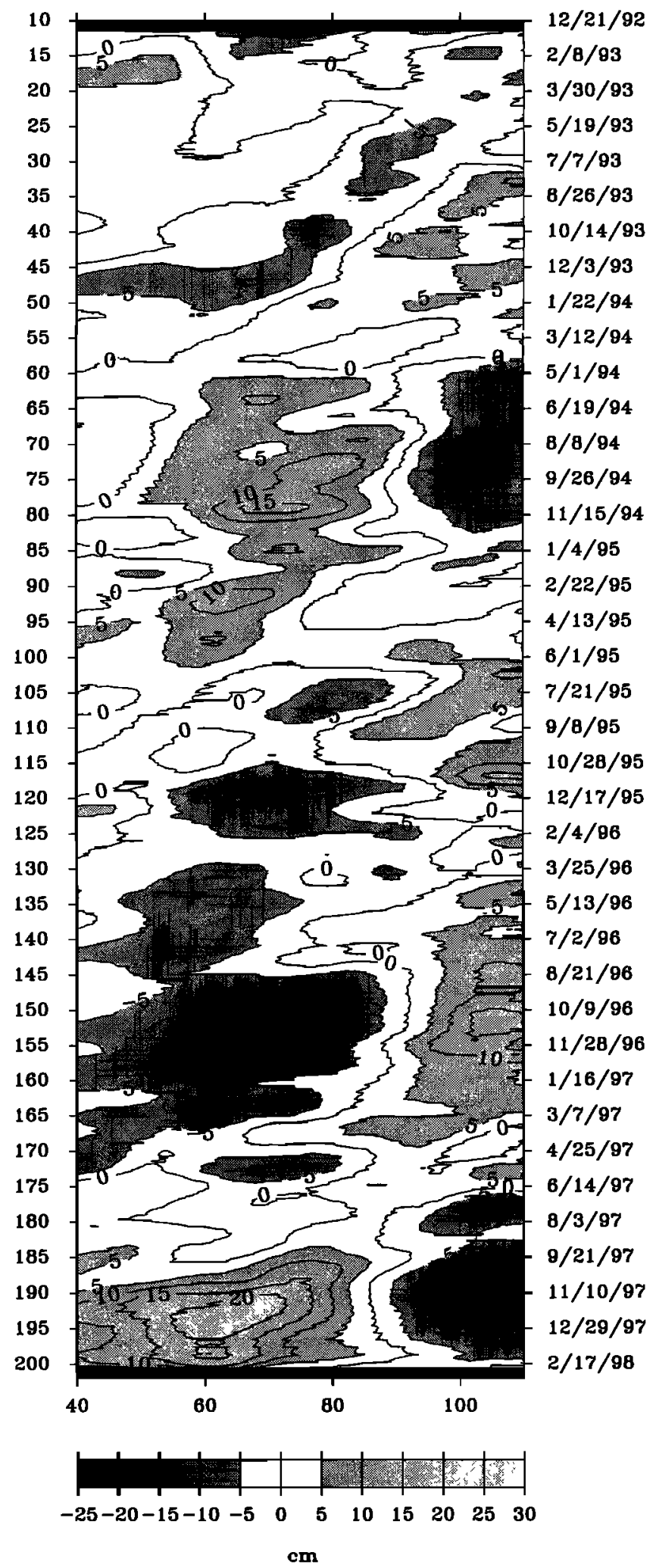

Figure 11. Time-longitude plot of T/P sea level anomalies in the Indian Ocean between $5^{\circ} \mathrm{S}$ and $9^{\circ} \mathrm{S}$, with a linear trend and annual and semiannual sinusoids removed. The left vertical axis is the T/P repeat cycle, the right vertical axis is the calendar date, and the horizontal axis is longitude in degrees east. Data have been additionally filtered in time with a 50-day running mean boxcar filter. Contour interval is $5 \mathrm{~cm}$. Anomalies smaller than $5 \mathrm{~cm}$ have been shaded dark gray, and anomalies greater than 5 $\mathrm{cm}$ have been shaded light gray. 


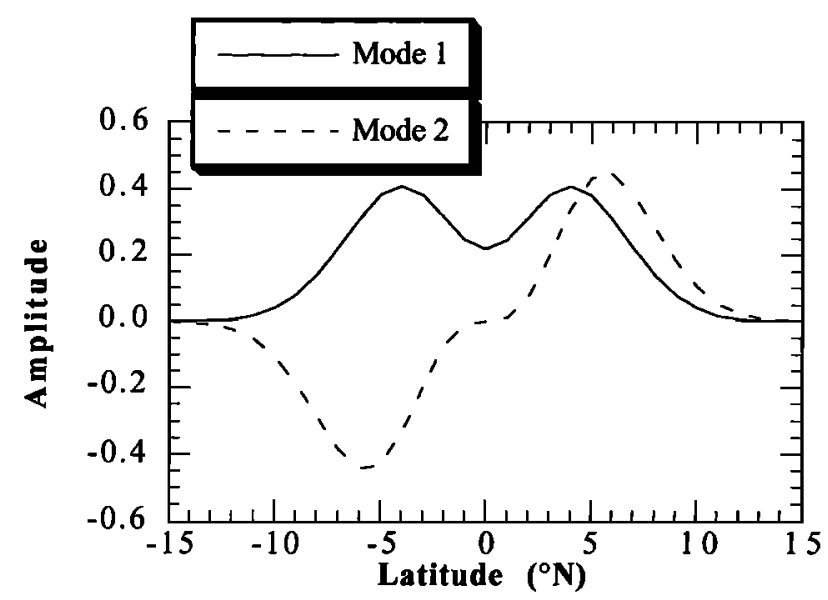

Figure 12. Theoretical meridional structure of first and second baroclinic Rossby wave modes.

be similar to that of the first or higher baroclinic modes. Boulanger and Menkes [1995] have presented a method to decompose sea level anomalies observed by altimetry into Rossby wave modes at particular longitudes and times. The technique estimates coefficients, $r_{n}(x, t)$, which when multiplied by the baroclinic wave mode meridional profile, $R_{n}(y)$, approximate the sea level elevation $\eta(x, y, t)$

$$
\eta(x, y, t)=\sum_{n=0}^{\infty} r_{n}(x, t) R_{n}(y)
$$

where $x$ and $y$ are the zonal and meridional (longitude and latitude) positions, $t$ is the time, and $n$ is the Rossby wave mode. The distances are nondimensionalized on an equatorial $\beta$ plane by the length scale $L=(c / \beta)^{1 / 2}$, and the series is generally truncated to $N$ modes. The 0 mode baroclinic phase speed $c$ is estimated to be between 2 to $3 \mathrm{~m} \mathrm{~s}^{-1}$. In this study, an average value of $2.5 \mathrm{~m}$ $\mathrm{s}^{-1}$ was used, and the series was truncated at $N=10$.

Using the gridded sea level anomalies and the theoretical meridional structure $R_{n}(y)$, the values of the coefficients $r_{n}(x, t)$ were estimated at each longitude for every repeat cycle in the area between $15^{\circ} \mathrm{S}-15^{\circ} \mathrm{N}$ and $50^{\circ} \mathrm{E}-110^{\circ} \mathrm{E}$, using the methodology outlined by Boulanger and Menkes [1995]. Figure 13 shows the mean of the coefficients in the area of largest wave activity $\left(60^{\circ} \mathrm{E}-80^{\circ} \mathrm{E}\right)$. The coefficients for the first and second baroclinic modes have the largest overall amplitudes. Positive values indicate downwelling Rossby waves, while negative values indicate upwelling Rossby waves. Large positive values for Mode 1 occur only in 1994/1995 and 1997, during the times of the interannual warming. There are also large negative coefficients present at the end of 1993, 1995, and 1996, which suggest upwelling waves. There is evidence of westwardly moving negative sea level anomalies in Figure 13 during these times which suggests correlations during La Niña. However, for this study we will continue to focus on the variability during the 1994 and 1997 El Niño events.

The coefficients of the second baroclinic mode are out of phase with those of the first mode; they are generally negative when the first mode coefficients are positive. Because of the structure of the second mode, this means that the T/P data observe a larger amplitude south of the equator than north of the equator. This is apparent in the T/P measurements at various longitudes and times in 1994 and 1997 (Figure 14). These locations were selected because they represent the largest sea level anomaly value in the Indian Ocean for particular T/P repeat cycles during the El Niño events.

The structure of the meridional sea level anomalies observed by T/P is similar at various longitudes both in 1994/1995 and
1997/1998. There is generally a peak between $10^{\circ} \mathrm{S}$ and $5^{\circ} \mathrm{S}$; the average position of the peak is about $7^{\circ} \mathrm{S}$, as noted previously. In 1997 there is a second peak with a smaller amplitude north of the equator at about $5^{\circ} \mathrm{N}$, although it tends to grow smaller as the wave moves westward. There is little evidence of a north peak in 1994.

Superimposed on the T/P observations are the theoretical first baroclinic mode extracted from the T/P data. Although the peak south of the equator observed by T/P is always $2^{\circ}$ to $5^{\circ}$ farther south than the peak predicted by theory, the amplitude of the decomposed mode is still significantly different from zero, particularly in 1997. There the first baroclinic Rossby wave mode has peak amplitudes between 10 to $20 \mathrm{~cm}$. The amplitudes for the 1994/1995 wave are smaller, of the order of about $5 \mathrm{~cm}$. However, a substantial amount of the difference can be attributed to the lack of a symmetric peak north of the equator.

If the second baroclinic mode is added to the first (Figure 14), then the amplitude south of the equator increases, while the amplitude north of the equator decreases due to the asymmetric nature of the second mode. In 1994/1995 the amplitudes south of $0^{\circ} \mathrm{N}$ increase to above $5 \mathrm{~cm}$ on every profile, and above $10 \mathrm{~cm}$ on several. In 1997 the amplitudes increase as well. The location of the peak observed by T/P is still south of the peak of the theoretical first and second baroclinic modes, however. Thus there appears to be significant power in the T/P sea level data at the first and second baroclinic Rossby wave modes, especially during the 1997 El Niño. It appears that both modes are present since the peaks are asymmetric about the equator. Because the south peak in the T/P data is consistently south of the peak predicted by theory, some other dynamics may also be at play, or there may be a limitation in the theory.

The phase speed of the waves observed by T/P should also be similar to phase speeds predicted for Rossby waves at that latitude. The linear theory of Rossby waves [Gill, 1982] predicts that the speed of a Rossby wave $c_{R}$ in the absence of mean currents is

$$
c_{R}=-c^{2} \beta / f^{2}
$$

where $f$ is the Coriolis parameter and $\beta$ is $d f / d y$. The value of $c_{R}$ depends strongly on the value selected for $c$, but typical values predicted for the speed of a Rossby wave at $5^{\circ}$ latitude is $-1 \mathrm{~m} \mathrm{~s}^{-1}$, where the negative sign indicates westward movement.

We have estimated the phase speed of the waves observed by T/P by two methods. In the first method, the longitude of the maximum positive sea level anomaly for each $1^{\circ}$ latitude for each repeat cycle was computed. The longitude values were plotted

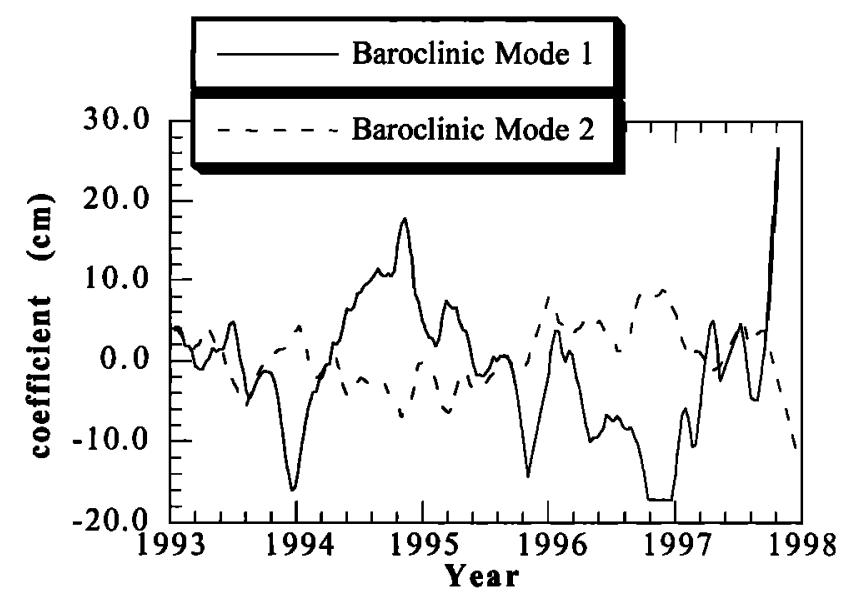

Figure 13. Averaged coefficients for first and second baroclinic wave modes extracted from T/P data. The coefficients have been averaged between $60^{\circ} \mathrm{E}$ and $80^{\circ} \mathrm{E}$. 

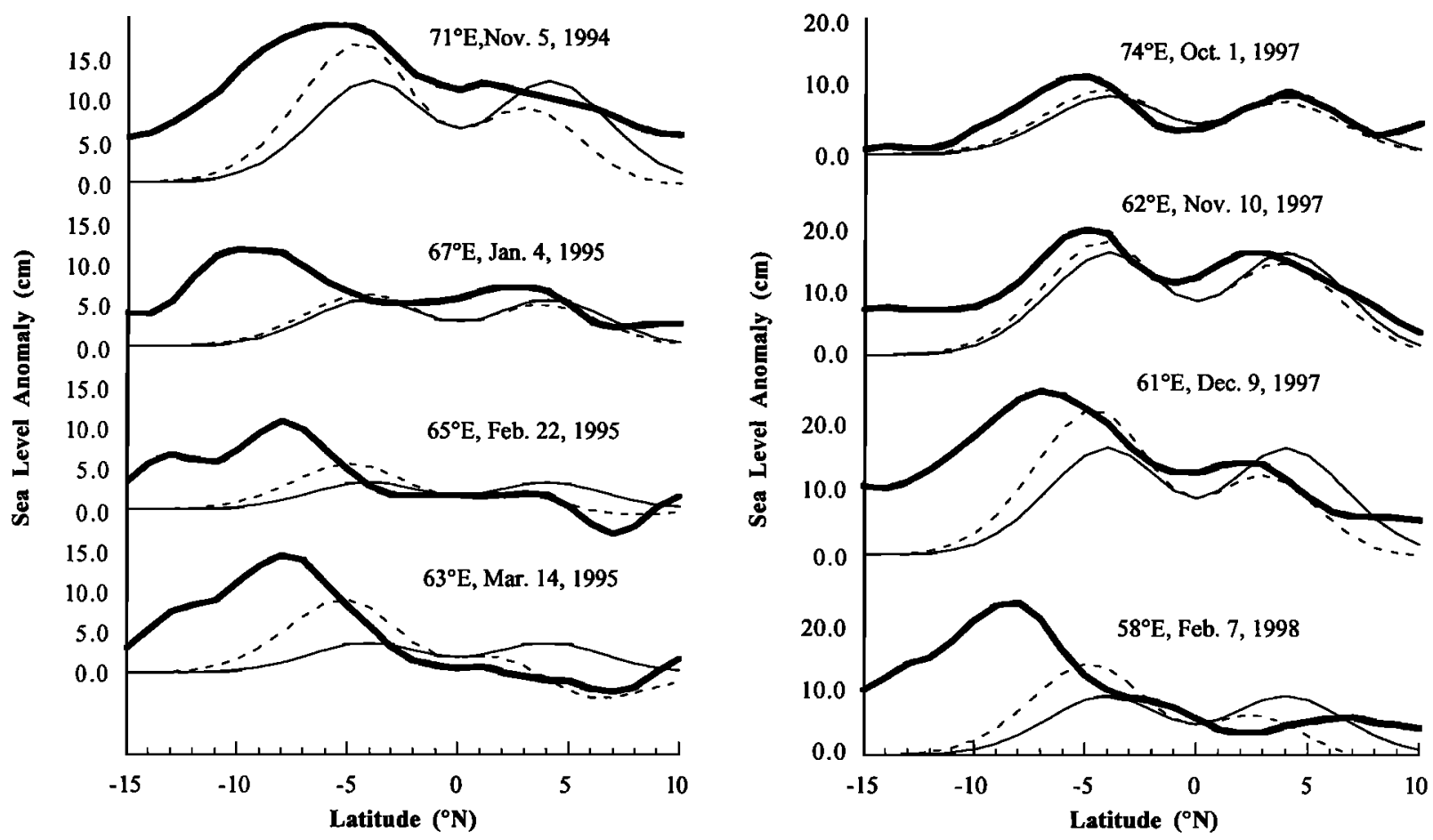

Figure 14. T/P sea level anomalies (thick solid lines) at extracted Rossby wave modes at various longitudes and times. The thin solid line is the first baroclinic wave mode, and the dashed thin line is the sum of the first and second wave modes. The longitudes were chosen as the longitude with the largest positive sea level anomaly for that particular time.

against repeat cycle for each $1^{\circ}$ band from $10^{\circ} \mathrm{S}$ to $4^{\circ} \mathrm{S}$, and the slope was estimated with a linear fit from T/P repeat cycle 75 to repeat cycle 95 (September 1994 through April 1995) and from repeat cycle 185 to repeat cycle 200 (September 1997 through February 1998). The estimated values ranged from -17 to $-35 \mathrm{~cm}$ $\mathrm{s}^{-1}$, with an error of $\pm 5 \mathrm{~cm} \mathrm{~s}^{-1}$ based on the covariance from the fit. We averaged the values for 1994 and 1997 and found mean values of about $-25 \mathrm{~cm} \mathrm{~s}^{-1}$ (Table 1).

We also estimated the phase speed by fitting a wave function to the sea level anomaly data, similar to the analysis used by Dayyani et al. [1996] to study Kelvin waves in the Pacific. The wave function $F$ was defined as

$$
F(x, y, t)=A R_{1}(y) \cos \left(k\left(x-c_{R} t\right)\right),
$$

where $R_{1}(y)$ is the meridional structure of the first baroclinic mode Rossby wave as described above, $k$ is the wave number, and $A$ is the amplitude. We seek to determine the values for $A, c_{R}$ and $k$ to minimize the merit function

$$
\chi^{2}=\sum_{i=1}^{P}\left(1 / \sigma^{2}\right)\left[\eta\left(x_{i} y_{v} t_{i}\right)-F\left(x_{i} y_{i} t_{i}\right)\right]^{2}
$$

Table 1. Rossby Wave Phase Speeds Estimated From T/P Altimeter Data

\begin{tabular}{lcc}
\hline $\begin{array}{c}\text { TOPEX } \\
\text { Microwave } \\
\text { Radiometer Minus }\end{array}$ & 1994 & 1997 \\
\hline Time-longitude & $-23 \pm 7$ & $-25 \pm 7$ \\
Wave function & $-29 \pm 15$ & $-24 \pm 10$ \\
\hline
\end{tabular}

Units are in $\mathrm{cm} \mathrm{s}^{-1}$. where $\eta\left(x_{t}, y_{t}, t_{t}\right)$ is the T/P observation, $P$ is the total number of observations, and $\sigma$ is the uncertainty in the measurements $\eta$. Here $\sigma$ was taken as a constant of $5 \mathrm{~cm}$. Although (4) is linear in the amplitude parameter, it is nonlinear in the phase speed and the wave number. Also, there is a one to one correlation between the phase speed and the wave number. Because of this, a nonlinear, iterative estimation scheme was used to estimate the parameters $A, c_{R}$, and $k$.

The iteration was done over various initial values of $c_{R}$ and $k$. Initial values of $c_{R}$ ranged from -3 to $3 \mathrm{~m} \mathrm{~s}^{-1}$ with $0.25 \mathrm{~m} \mathrm{~s}^{-1}$ step sizes, while values for wavelength $(2 \pi / k)$ ranged from 3000 to $8000 \mathrm{~km}$ with $200 \mathrm{~km}$ step sizes. The amplitude parameter was initialized with a value of 10 . The parameters were updated using the Levenberg-Marquardt nonlinear estimation method [Press et al., 1992], and (5) was recomputed with the new estimates. The procedure was repeated to estimate new values of the parameters until $\chi^{2}$ changed by less than 1 , or the procedure had iterated more than 10 times. The final value of $\chi^{2} / P$ (approximately equal to the variance of the residual) and the estimated parameters were recorded, and the procedure was stepped through with new initial conditions.

From the output a global minimum was determined. The procedure was run over the two time spans with the most significant wave activity, September 26, 1994, to March 13, 1995 (T/P cycles 80 to 95 ) and September 21, 1997, to December 29, 1997 (T/P cycles 185 to 195). The gridded sea level anomaly data between $12^{\circ} \mathrm{S}-0^{\circ} \mathrm{N}$ and $50^{\circ} \mathrm{E}-90^{\circ} \mathrm{E}$ were used as observations. The phase speeds which gave the minimum variance $\left(\chi^{2} / P\right)$ are recorded in Table 1 . The errors come from the covariance matrix obtained in the estimation.

The values are very close to those obtained from plotting the longitude of maximum sea level versus time. One measure of how well the wave function fits the data is to examine the difference between the final value of $\chi^{2} / P$ and the value of $\chi^{2 / P}$ computed when $F=0$, that is, the variance of the observations. 


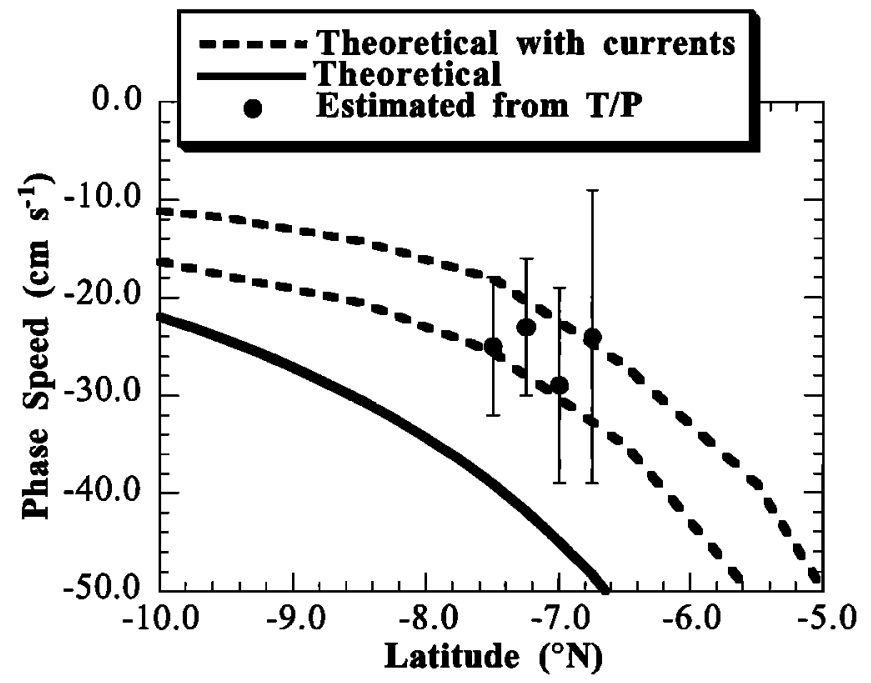

Figure 15. Curves of theoretical Rossby wave speed as a function of latitude (thick solid curve) and theoretical Rossby wave speed in the presence of mean currents for June and October (dashed curves), along with estimates of wave speeds observed by T/P (solid circles). The observed phase speeds are grouped around $7^{\circ} \mathrm{S}$ because this is the region of largest sea level variability.

The final value of $\chi^{2} / P$ should be significantly smaller than the variance of the observations if there is a detectable wave in the observations. For the wave associated with the $1997 \mathrm{El} \mathrm{Niño,} \mathrm{the}$ value for $\chi^{2} / P$ is 2.4 , while the variance of the observations is 5.7 , suggesting that the wave explains nearly $60 \%$ of the variation in sea level. The estimation in 1994 is not as good. In 1994 the value for $\chi^{2} / P$ is 0.8 , while the variance of the observations is 1.1 , suggesting that the wave explains only $30 \%$ of the variation in sea level. The parameters of the 1994 wave are much harder to estimate, however, because of the lower overall signal in the sea level anomaly data.

Figure 15 shows the waves speeds estimated from the T/P data along with the theoretical Rossby wave speed as a function of latitude from (3), using $c=2.5 \mathrm{~m} \mathrm{~s}^{-1}$. The estimated speeds are given around $7^{\circ} \mathrm{S}$ since that is where the sea level variations are the largest. The speeds estimated from the T/P observations are significantly smaller than those predicted by theory, even considering the error bars on the estimates. However, recall that (3) was derived assuming that there are no mean background currents. At this location in the Indian Ocean, though, the zonal surface currents cannot necessarily be ignored. Chang and Philander [1988] studied the effect of mean currents in the tropical Pacific on Rossby wave propagation and found that the slope of the thermocline associated with the background currents can cause significant departures from the theoretical phase speed. They found that the shallower the thermocline the slower the waves were than that predicted by theory.

The relationship between phase speed to thermocline depth is approximated by Philander [1990]

$$
c_{R}=-g^{\prime} H(y) \beta / f^{2},
$$

where $g^{\prime}=g\left(\rho_{2}-\rho_{1}\right) / \rho_{2}$, the reduced gravity, and $H(y)$ is the depth of the thermocline. The parameter $g$ is the acceleration due to gravity, and $\rho$ is density. The subscripts denote density in a two-layer model, with 1 indicating the upper layer and 2 the lower layer. The thermocline depth was determined for each $1^{\circ}$ grid in the region $15^{\circ} \mathrm{S}-15^{\circ} \mathrm{N}$ and $50^{\circ} \mathrm{E}-90^{\circ} \mathrm{E}$ using climatological data from the World Ocean Atlas [Levitus and
Boyer, 1994; Levitus et al., 1994]. The depth of the thermocline was estimated as the depth of the largest temperature gradient with respect to depth, using a finite forward/backward difference. The values for each $1^{\circ}$ grid were then averaged together for each latitude band over the longitude extent. The reduced gravity was averaged over the region $10^{\circ} \mathrm{S}$ to $5^{\circ} \mathrm{S}, 50^{\circ} \mathrm{E}-90^{\circ} \mathrm{E}$, using densities determined from the climatological temperature and salinity values in the World Ocean Atlas. The value used for reduced gravity was 0.04 .

Values for $c_{R}$ were then computed for each latitude using (6) and are shown in Figure 15. To take into account the fact that the thermocline changes due to seasonal wind forcing and heat flux, $c_{R}$ curves were computed for October and February thermocline profiles. This covers the range of time that the waves observed by $\mathrm{T} / \mathrm{P}$ cross the Indian Ocean. As can be seen in Figure 15, the wave phase speeds estimated from the $T / P$ data are consistent with Rossby wave phase speeds if the mean background currents are accounted for by using (6) instead of (3).

\section{Conclusions}

Based on this study and those of previous investigators [Tourre and White, 1995; Nicholson, 1997], it has become clear that the atmospheric effects which drive El Niño in the Pacific cause similar interannual warming anomalies in the Indian Ocean. The Indian Ocean warming appears as a near mirror image to the Pacific warming, with the largest warming occurring in the southwestern equatorial Indian Ocean. Satellite altimeter data, because of its dense coverage, has proven important in accurately determining where the peak heating occurs in the Indian Ocean and how the warming evolves. An analysis of the altimeter data shows that a significant portion of the sea level variability in the Indian Ocean during the 1994 and 1997 El Niños was related to Rossby waves. The variability followed westwardly wind anomalies in the east-central Indian Ocean.

Based on the altimeter and wind observations, the following hypothesis describing the initiation and evolution of the Indian Ocean warming has been developed. It appears that westwardly wind anomalies in the central Indian Ocean connected with the Southern Oscillation excite downwelling Rossby waves, which move westward and depress the thermocline in the southwestern Indian Ocean several months later. This is similar to the forcing of Kelvin waves in the equatorial Pacific that depress the thermocline in the eastern Pacific during El Niño. The warming appears to be strengthened by Ekman transport of warm water from Indonesia due to wind anomalies along the eastern coast. The warming begins below the surface, then moves to the surface, similar to the signal in the Pacific. This explains why the SST variations lag the sea level variations. Thus it appears that El Niño is not solely a Pacific Ocean phenomenon but that it is bimodal with distinct signals in both the Pacific and the Indian Oceans.

This may explain the correlations between El Niño and the Asian monsoons and African rainfall that have been observed [Joseph et al., 1994; Nigam, 1994; Kumar et al., 1995; Charles et al., 1997]. It is likely that at least part of the correlation is due to the warming in the Indian Ocean which is correlated with El Niño, although Nigam and Shen [1993] conclude that the surface warming is not large enough to cause the atmospheric variations. More work is needed to quantify the relation. Although we have presented strong evidence that the interannual warming in the Indian Ocean is driven by Rossby waves during 1994 and 1997, more work needs to be done to verify this for earlier El Niño events. The SST analysis presented here and the results of previous studies [Tourre and White, 1995; Nicholson, 1997] indicate that the Indian Ocean warming has tended to occur during the Pacific El Niño for the last 50 years, although it is not clear if it progressed in the same fashion as it did in 1994 and 1997. The fact that the Indian Ocean wind anomalies are similar 
for E1 Niño events before 1994 strongly suggests that Rossby wave forcing did occur. Since direct measurements of these Rossby waves will be difficult without satellite altimeter data, perhaps the only way to study the Indian Ocean Rossby wave activity during earlier El Niño events is with numerical models forced by observed winds.

Acknowledgments. The authors would like to thank Steve Nerem and Rick Pastor for the original version of the EOF software used in this study. We would also like to thank Sharon Nicholson and an anonymous reviewer for their comments which helped us improve this paper. TOPEX/POSEIDON data are from the Physical Oceanography Data Archive Center at Jet Propulsion Laboratory/California Institute of Technology. The Reynolds SST data are from the data archive at the National Oceanic and Atmospheric Administration National Center for Environmental Prediction. The winds pseudostress data are from the quick-look data archive at the Center of Ocean-Atmospheric Prediction Studies at Florida State University. This research was supported by NASA Grant NAG5-5094.

\section{References}

Benada, R., TOPEX/POSEIDON merged GDR generation B user's handbook, JPL Rep. D-11007, Jet. Propul. Lab.,Pasadena, Calif., 1997.

Boulanger, J.-P. and L.-L. Fu, Evidence of boundary reflection of Kelvin and first-mode Rossby waves from TOPEX/POSEIDON sea level data, J. Geophys. Res., 101, 16361-16371, 1996.

Boulanger, J.-P. and C. Menkes, Propagation and reflection of long equatorial waves in the Pacific Ocean during the 1992-1993 El Niño, J. Geophys. Res., 100, 25041-25060, 1995.

Chambers, D. P., B. D. Tapley, and R. H. Stewart, Long-period ocean heat storage rates and basin-scale heat fluxes from TOPEX, $J$. Geophys. Res., 102 , 10525-10533, 1997.

Chambers, D. P., B. D. Tapley, and R. H. Stewart, Measuring heatstorage changes in the equatorial Pacific: A comparison between TOPEX altimetry and TAO buoys, J. Geophys. Res., $103,18591-$ 18597, 1998a.

Chambers, D. P., B. D. Tapley, and R. H. Stewart, Reduction of geoid gradient error in ocean variability from satellite altimetry, Mar. Geod., $21,25-39,1998 \mathrm{~b}$.

Chambers, D. P., J. C. Ries, C. K. Shum, and B. D. Tapley, On the use of tide gauges to calibrate altimeter drift, $J$. Geophys. Res., J03, 12885$12890,1998 \mathrm{c}$

Chang, P. and S. G. H. Philander, Rossby wave packets in baroclinic currents, Deep Sea Res., 36, 17-37, 1988.

Charles, C. D., D. E. Hunter, and R. G. Fairbanks, Interaction between the ENSO and the Asian monsoon in coral record of tropical climate, Science, 277, 925-928, 1997.

Chelton, D. B., and M. G. Schlax, Global observations of oceanic Rossby waves, Science, 272, 234-238, 1996.

Climate Analysis Center, Climate Diagnostics Bulletin: Near Real-Time Analyses Ocean/Atmosphere, U.S. Dep. of Comm., Camp Springs, Md., June-August, 1994.

Climate Analysis Center, Climate Diagnostics Bulletin: Near Real-Time Analyses Ocean/Atmosphere, U.S. Dep. of Comm., Camp Springs, Md., May-August, 1997a.

Climate Analysis Center, Climate Diagnostics Bulletin: Near Real-Time Analyses Ocean/Atmosphere, U.S. Dep. of Comm., Camp Springs, Md., October, 1997b.

Dayyani, B., P. D. Weidman, and G. H. Bom, Detection of ocean waves using satellite altimetry: application to equatorial Kelvin waves, Mar. Geod., 19, 359-385, 1996.

Delcroix, T., and J. Picaut, Zonal displacement of the western equatorial Pacific "fresh pool," J. Geophys. Res., 103, 1087-1098, 1998.

Delcroix, T., J. Picaut, and G. Eldin, Equatorial Kelvin and Rossby waves evidenced in the Pacific Ocean through Geosat sea level and surface current anomalies, J. Geophys. Res., 96, 3249-3262, 1991.

Gill, A. E., Atmosphere-Ocean Dynamics, 662 pp., Academic, San Diego, Calif., 1982.
Goddard, L., and N. E. Graham, El Niño in the 1990s, J. Geophys. Res., $102,10423-10436,1997$.

Graham, N. E., and W. B. White, The El Niño cycle: A natural oscillator of the Pacific ocean-atmosphere system, Science, 240, 1293-1302, 1988.

Harrison, D. E. and P. S. Schopf, Kelvin wave induced anomalous advection and the onset of SST warming in El Nino events, Mon. Weather Rev., 112, 923-933, 1984.

Joseph, P. U., J. K. Eischeid, and R. J. Pyle, Interannual variability of the onset of Indian Summer monsoon and its association with atmospheric features, El Niño, and sea surface temperature anomalies, J. Clim., 7, 81-105, 1994

Kumar, K. K., M. K. Soman, and K. R. Kumar, Seasonal forecasting of Indian summer monsoon rainfall: A review, Weather, 50, 449-467, 1995.

Legler, D. M. and J. J. O'Brien, Atlas of Tropical Pacific Wind-Stress Climatology: 1971 1980, Florida State University, Tallahassee, Florida, $187 \mathrm{pp}, 1985$.

Levitus, S., and T. P. Boyer, World Ocean Atlas 1994, vol. 4, Temperature, NOAA Atlas NESDIS 4, 117 pp., Natl. Oceanogr. Data Cent., Silver Spring, Md., 1994.

Levitus, S., R. Burgett, and T. P. Boyer, World Ocean Atlas 1994 vol. 3, Salinity, NOAA Atlas NESDIS 3, 99 pp., Natl. Oceanogr. Data Cent., Silver Spring, Md., 1994.

Miller, L., R. E. Cheney, and B. C. Douglas, Geosat altimeter observations of Kelvin waves and the 1986-1987 El Niño, Science, $239,52-54,1988$.

Nicholson, S. E., An analysis of the El Niño signal in the tropical Atlantic and western Indian Oceans, Int. J. Climatol., I7, 345-375, 1997.

Nigam, S., On the dynamical basis for the Asian summer monsoon rainfall-El Niño relationship, J. Clim., 7, 1750-1771, 1994.

Nigam, S., and H. S. Shen, Structure of atmospheric low-frequency variability over the tropical Pacific and Indian Oceans, 1, COADS observations, J. Clim., 6, 657-676, 1993.

Philander, S. G., El Niño, La Niña and the Southern Oscillation, 293 pp., Academic, San Diego, Calif., 1990.

Philander, S. G., and R. C. Pacanowski, The generation of equatorial currents, J. Geophys. Res., 85, 1123-1136, 1980.

Preisendorfer, R. W., Principal Component Analysis in Meteorology and Oceanography, edited by C. Mobley , 418 pp., Elsevier Sci., New York, 1988.

Press, W. H., S. A. Teukolsky, W. T. Vetterling, and B. P. Flannery, Numerical Recipes in Fortran 77: The Art of Scientific Computing, $2^{\text {md }}$ ed., pp. 675-683, Cambridge Univ. Press, New York, 1992.

Reynolds, R. W., A real-time global sea surface temperature analysis, $J$. Clim., 1, 75-86, 1988.

Reynolds, R. W., and T. M. Smith, Improved global sea surface temperature analysis using optimum interpolation, J. Clim., 7, 929948, 1994

Stricherz, J., D. M. Legler, and J. J. O'Brien, Atlas of Florida State University Indian Ocean Winds for TOGA 1970-1985, 250 pp., Fl. State Univ., Tallahassee, 1993.

Tourre, Y. M., and W. B. White, El Niño signals in the global upperocean temperature, J. Phys. Oceanogr., 25, 1317-1332, 1995.

Wang, L., and C. Koblinsky, Can the TOPEX/POSEIDON altimetry data be used to estimate air-sea heat flux in North Atlantic, Geophys. Res. Lett., 24, 139-142, 1997.

White, W. B. and C. K. Tai, Inferring interannual changes in global upper ocean heat storage from TOPEX altimetry, J. Geophys. Res., 100, 24943-24954, 1995.

Yang, J., L. Yu, C. J. Koblinsky, and D. Adamec, Dynamics of the seasonal variations in the Indian Ocean from TOPEX/POSEIDON sea surface height and an ocean model, Geophys. Res. Lett., 25, 1915. $1918,1998$.

D. P. Chambers (corresponding author) and B. D. Tapley, Center for Space Research, University of Texas, 3925 W. Braker Lane, Suite 200, Austin, TX 78759-5321. (chambers@csr.utexas.edu)

R. H. Stewart, Department of Oceanography, Texas A \& M University, College Station, TX 77843.

(Received November 20, 1994, revised November 4, 1998, accepted November 16, 1998.) 